\title{
Stability Improvement of Onboard HVDC Grid and Engine Using an Advanced Power Generation Center for the More-Electric Aircraft
}

\author{
Xiaoyu Lang, Tao Yang, Senior Member, IEEE, Zhen Huang, Member, IEEE, Cheng Wang, Zhenyu Wang, \\ Serhiy Bozhko, Senior Member, IEEE, and Patrick Wheeler, Fellow, IEEE
}

\begin{abstract}
In the high-power settings of engine, such as maximum take-off, more power should be extracted from the high-pressure spool (HPS) than the low-pressure spool (LPS) to avoid the overspeed and potential instability of the HPS. However, as revealed in this paper, extracting more power from the HPS will degrade the onboard HVDC grid stability for the conventional single dc bus power generation center. To address this conflict, in this paper, an advanced power generation center (APGC) incorporating an extra back-to-back (BTB) converter is introduced to improve the stability for both engine and HVDC grid. The BTB converter connects the HP power generation channel and the LP channel, providing an additional power flow path between the HP channel and LP channel. A transfer function-based impedance model and a state-space model of the HVDC grid are proposed to study the HVDC grid stability. The analytical findings of the HVDC grid stability and stability improvement using the APGC architecture have been verified through simulation and experimental results.
\end{abstract}

Index Terms - Power generation system, more-electric aircraft (MEA), voltage stability, power control, dc power system, multiple power sources.

\begin{tabular}{|c|c|}
\hline \multicolumn{2}{|r|}{ Nomenclature } \\
\hline APGC & Advanced power generation center \\
\hline BTB converter & Back-to-back converter \\
\hline HP & High-pressure \\
\hline LP & Low-pressure \\
\hline HPR & The high-pressure channel rectifier \\
\hline LPR & The low-pressure channel rectifier \\
\hline HPS & The high-pressure spool of engine \\
\hline LPS & The low-pressure spool of engine \\
\hline HPG & $\begin{array}{l}\text { The generator coupled to the high-pressure } \\
\text { spool of engine }\end{array}$ \\
\hline LPG & $\begin{array}{l}\text { The generator coupled to the low-pressure } \\
\text { spool of engine }\end{array}$ \\
\hline HVDC & High-voltage direct current \\
\hline
\end{tabular}

\section{INTRODUCTION}

The more-electric aircraft (MEA) concept is one of the major trends for the modern aerospace industry. Greenhouse gases emission and fuel consumption can be significantly reduced, and low maintenance cost can be achieved with MEA technology [1]. Existing onboard components which consume mechanical, pneumatic, and hydraulic energies are replaced by their electrical counterparts [2]. Consequently, electrical power (EP) generation systems with sufficient power supply capability should be deployed in MEA.

This work was supported by Clean Sky 2 Joint Undertaking under the European Union's Horizon 2020 research and innovation program under Grant 807081. (Corresponding author: Cheng Wang.)

X. Lang, T. Yang, Z. Wang, C. Wang, S. Bozhko, and P. Wheeler are with the Power Electronics, Machines and Control Group, The University of Nottingham, Nottingham, NG7 2RD, U.K. (e-mail: xiaoyu.lang @nottingham.ac.uk; tao.yang@nottingham.ac.uk; ezzzw1@exmail. nottingham.ac.uk; eexcw13@exmail.nottingham.ac.uk; serhiy.bozhko@ nottingham.ac.uk; pat.wheeler@ nottingham.ac.uk).
For most commercial aircrafts, their engines are designed with a twin-spool structure: a low-pressure spool (LPS) and a high-pressure spool (HPS). The LPS connects the fan, low-pressure compressor (LPC) and low-pressure turbine (LPT). The HPS links the axial and radial highpressure compressors (HPCs) and high-pressure turbine (HPT). Conventionally, generators are coupled to the HPS because the HPS features a relatively high and constant speed. This enables engineers to minimize the weight and size of the coupled high-pressure spool generator (HPG) [3].

However, this single generator architecture is not optimal considering the significant power demand of MEA. It has been revealed that if too much power is extracted only from the HPS, compressor surge, which is a critical threat to engine operation will occur [4]. Although solutions such as excessive bleedings between compressor stages or oversizing the HPT can address this issue, the actions will cost extra fuel and result in undesirable thrust.

To cope with the high-power demand without undesirable fuel waste or thrust, an effective way is to add an extra low-pressure spool generator (LPG), converting the mechanical power (MP) of the LPS into EP. Considering the different speed range of the LPS and HPS (the range of the HPS is typically 1:2, e.g., 10,000$20,000 \mathrm{rpm}$. That of the LPS is 1:4, e.g., 1,000-5,000rpm [5]), it indicates different fundamental ac frequencies of the LPG and HPG. Consequently, it is unrealistic to directly construct an ac bus due to the frequency conflict. Alternatively, one can independently control the LPG and HPG via two rectifiers and then connecting their dc terminals to a common de bus [6].

Therefore, this gives a dual-generator-single-dc-bus power generation center (PGC) as shown in Fig. 1 [7]-[11]. In Fig. 1, the two generators are independently regulated by two rectifiers, denoting as the LPR and HPR, respectively. A variety of onboard loads and energy management components can absorb power from this dc bus [12]. It has been verified that this PGC can not only efficiently exploit the power of engine, but also improve the onboard dc grid redundancy and power quality [7]-[11].

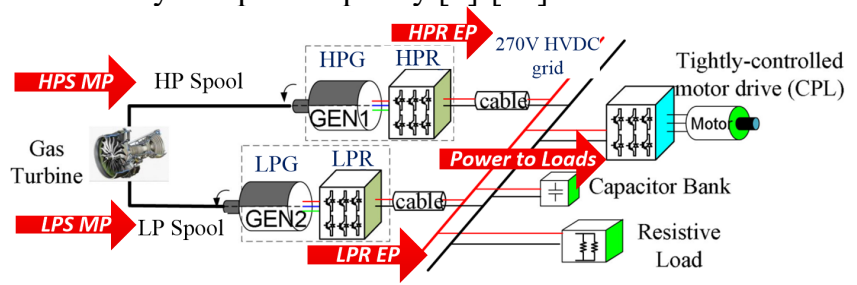

Fig. 1 The PGC with two generators and single de bus configuration.

However, the PGC in Fig. 1 suffers from the "Power Coupling Effect" (PCE) between the MP of engine spools and the EP delivered by rectifiers. As can be seen from the 
red arrows in Fig. 1, the EP of the HPR is extracted from the MP of the HPS. he EP of the LPR comes from the MP of the LPS. The feature that electrical power is coupled to the mechanical power is defined as Power Coupling Effect, which is

$$
\begin{aligned}
H P \text { Channel: } H P R \text { 's } E P & =H P S \text { 's } M P \\
L P \text { Channel: } L P R \text { 's } E P & =L P S \text { 's } M P
\end{aligned}
$$

The Power Coupling Effect makes the HVDC grid stability and the engine stability show the opposite trend. Improving one of the stabilities will degrade the other. For improving stability of the HVDC gird, this paper proves that the LPR is expected to feed more electrical power than the HPR to the dc bus. Due to the PCE, this means that more mechanical power is extracted from the LPS than the HPS. However, in the high-power settings of engine, such as maximum take-off and top of climb, the HPS should provide more MP than the LPS to avoid the overspeed and potential instability of the HPS [13], [14]. Apparently, the PGC with Power Coupling Effect in Fig. 1 cannot handle this conflict.

To address the PCE and achieve stability improvement for both engine and HVDC grid, an advanced power generation center (APGC) with a back-to-back (BTB) converter is introduced in Fig. 2. The BTB converter connects the ac terminals of the LPG and HPG. It can transfer power between the HP and LP power generation channels. From the viewpoint of power, as the red arrows shown in Fig. 2, the APGC has the following feature $H P$ Channel: $H P S M P=H P G E P=H P R E P+/-B T B E P$ $L P$ Channel: $L P S M P=L P G E P=L P R E P-/+B T B E P$

Hence, this BTB converter can be regarded as a power decoupling bridge. More mechanical power can be extracted from the HPS than the LPS for preventing overspeed of the HPS. On the other hand, the LPR can share more power than the HPR to improve the HVDC grid stability. This favorable feature makes this APGC more flexible in terms of power flow and the stability of both engine and HVDC gird can be enhanced.

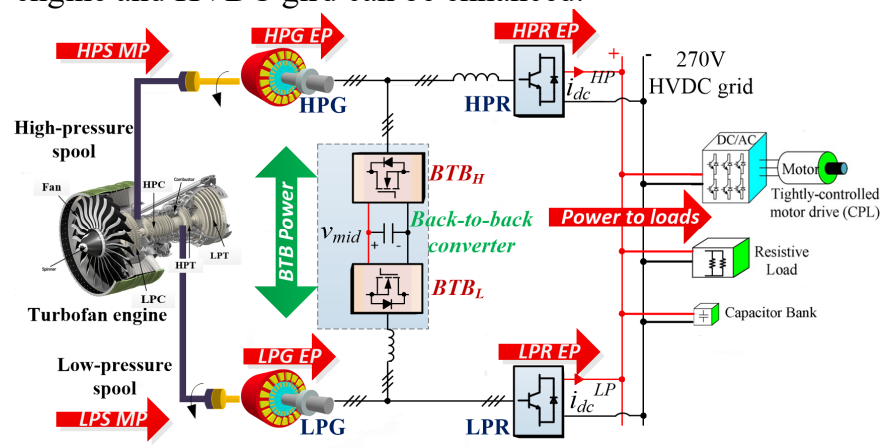

Fig. 2. Configuration of the APGC.

The APGC shown in Fig. 2 was firstly presented in our previous work [11], which focuses on the elimination of field weakening operation of the HPG at a high speed. A $5 \%$ efficiency improvement is achieved under $10 \mathrm{~kW}$ load condition. This paper will focus on the power decoupling characteristic of the APGC. The main findings and contributions of this paper are highlighted as follows:

1) A new concept named Power Coupling Effect is defined and analyzed for the first time.

2) An onboard HVDC grid equivalent circuit is built. By analyzing this equivalent circuit it reveals that increasing the proportion of the LPR's power can improve stability of the HVDC grid.

3) Simulation and experiments are carried out, proving that the APGC can address the Power Coupling Effect and enhance both the engine and HVDC grid stability.

The rest of this paper is organized as follows. In Section II, an adaptive control design for the rectifiers is carried out. The derived dc current dynamics is further used for stability analysis in the next section. In Section III, a dc side equivalent circuit is established for assessing the HVDC grid stability. In section IV and V, control performances of the APGC and stability improvement for engine and HVDC grid are validated in simulations and experiments. Section VI concludes this paper.

\section{ADAPTIVE CONTROL DESIGN FOR THE RECTIFIERS}

The control scheme for both the HP and LP rectifiers are given in Fig. 3. Since both the HPR and LPR supply power to a common dc bus, suitable power sharing strategy should be applied. In this study, a decentralized droop control [15] is adopted for the power sharing purpose. The $\mathrm{dc}$ current reference is generated depending on the dc bus voltage and the predefined $V-I$ droop characteristic, which is shown in the following

$$
i_{d c}^{r e f}=\frac{v_{d c}^{r e f}-v_{d c}}{k_{D}}
$$

where $k_{D}$ is the droop gain. $i_{d c}{ }^{r e f}$ is the dc current command. $v_{d c}$ and $v_{d c}{ }^{r e f}$ are the actual and nominal dc voltage, respectively.

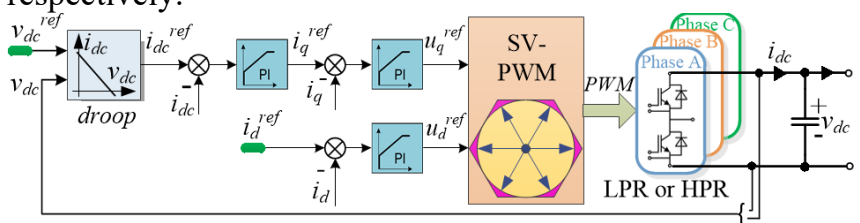

Fig. 3. Control scheme with the droop control and the de voltage control for both the HP and LP rectifiers.

The system dynamic behavior is strongly related to the type of generators. Due to high power density, high efficiency and wide speed range, permanent magnet generators (PMGs) appear as a favorable option for the MEA application [16]. The electrical dynamics of PMG in $d q$ rotary frame are shown as follows [17]:

$$
\left\{\begin{array}{l}
\frac{d i_{d}}{d t}=\frac{1}{L_{d}}\left(u_{d}-R_{s} i_{d}+\omega_{e} L_{q} i_{q}\right) \\
\frac{d i_{q}}{d t}=\frac{1}{L_{q}}\left(u_{q}-R_{s} i_{q}-\omega_{e} L_{d} i_{d}-\omega_{e} \psi_{f}\right)
\end{array}\right.
$$

where $u_{d}, u_{q}$ are the $d q$-axes stator voltages. $L_{d}, L_{q}$ are the $d q$-axes stator inductance. $R_{s}$ is the stator resistance. $\psi_{f}$ is the flux linkage of the rotor permanent magnet. $\omega_{e}$ is the electrical angular speed in $\mathrm{rad} / \mathrm{s}$.

The electrical dynamics in (2) can be transformed into the Laplace domain as follows:

$$
\left\{\begin{array}{l}
u_{d}=\left(R_{s}+L_{d} s\right) i_{d}-\omega_{e} L_{q} i_{q} \\
u_{q}=\left(R_{s}+L_{q} s\right) i_{q}+\omega_{e} L_{d} i_{d}+\omega_{e} \psi_{f}
\end{array}\right.
$$

Considering the fact that time constant of the mechanical system is much larger than that of the electrical system due to the large spool inertia of the engine, speed $\omega_{e}$ can be regarded as unchanged during successive electrical 
control period. Hence, the increment of variables in (3) can be expressed as follows

$$
\left\{\begin{array}{l}
\Delta u_{d}=\left(R_{s}+L_{d} s\right) \Delta i_{d}-\omega_{e} L_{q} \Delta i_{q} \\
\Delta u_{q}=\left(R_{s}+L_{q} s\right) \Delta i_{q}+\omega_{e} L_{d} \Delta i_{d}
\end{array}\right.
$$

Due to the presence of the BTB converter, the currents of generators are different from that of the rectifiers. Here the LP side power generation channel is considered. The schematic is shown in Fig. 4. To remove the Power Coupling Effect, the BTB converter transfers power from the HP channel to the LP channel in the high-power settings of engine. Hence, the following relationships can be obtained

$$
i_{a L P R}=i_{a L}+i_{a B T B L} \quad i_{b L P R}=i_{b L}+i_{b B T B L} \quad i_{c L P R}=i_{C L}+i_{c B T B L}
$$

where $i_{x L}$ is the phase currents of the LPG; $i_{x L P R}$ are the phase currents of the LPR; $i_{x B T B L}$ represent the ac phase currents of the $\mathrm{BTB}_{\mathrm{L}}$ converter. $x=a, b, c$.

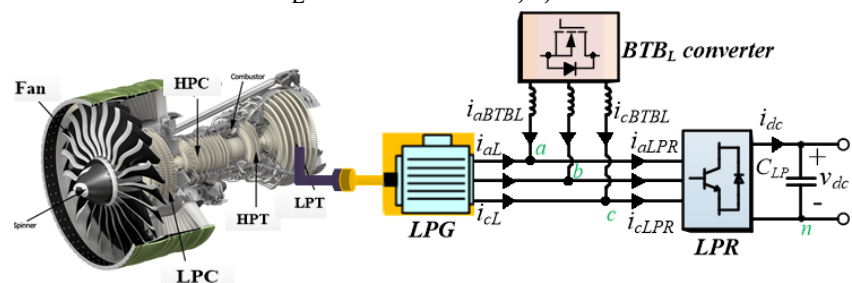

Fig. 4. The schematic of the LP channel with the LPG, the LPR and the $\mathrm{BTB}_{\mathrm{L}}$ converter.

A current synchronization strategy is used to regulate the power of BTB converter. Details are presented in [11]. By applying this strategy, the BTB converter mainly transfers active power. Hence, the following relationships in steady state in $d q$ rotary frame can be obtained

$$
i_{d L P R}=i_{d L} \quad i_{q L P R}=i_{q L}+i_{q B T B L}
$$

where $i_{d L}, i_{q L}$ are the $d q$-axes stator currents of the LPG. $i_{d L P R}, i_{q L P R}$ are the $d q$-axes currents of the LPR. $i_{q B T B L}$ is the $q$-axis current of the $\mathrm{BTB}_{\mathrm{L}}$ converter.

Subsequently, according to Fig. $\mathbf{4}$, the ac side power and dc side power of the LPR can be expressed as

$$
\left\{\begin{array}{l}
P_{a c}=\frac{3}{2}\left(u_{d} i_{d L P R}+u_{q} i_{q L P R}\right)=\frac{3}{2}\left[u_{d} i_{d L}+u_{q}\left(i_{q L}+i_{q B T B L}\right)\right] \\
P_{d c}=v_{d c} i_{d c L P}
\end{array}\right.
$$

The relation in (7) can be further linearized as follows

$$
\frac{3}{2}\left(\Delta u_{d} \bar{i}_{d L}+\bar{u}_{d} \Delta i_{d L}+\Delta u_{q} \bar{i}_{q L}+\bar{u}_{q} \Delta i_{q L}\right)+\Delta \varepsilon_{q}=\bar{v}_{d c} \Delta i_{d c}+\bar{i}_{d c} \Delta v_{d c}(8)
$$

where the superscript "-" means a stable operating point. $\Delta \varepsilon_{q}$ is a lumped term incorporating $i_{q B T B L}$.

According to the control scheme in Fig. 3, the control block diagram for the LPR can be obtained in Fig. 5, where $G_{c}(s)$ is the inner-current loop dynamics, $G_{i q \_d c}(s)$ is the dynamics from $\Delta i_{q L}$ to $\Delta i_{d c}$. $C_{L P}$ is the capacitance of the dc bus capacitor. $1 /\left(C_{L P} S+\bar{P} / \bar{v}_{d c}^{2}\right)$ is the transfer function from the dc current $\Delta i_{d c}$ to the dc voltage $\Delta v_{d c}$, where $\bar{P}$ is the load power.

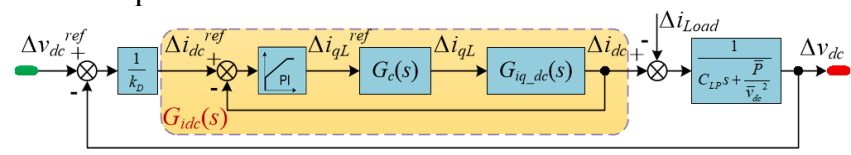

Fig. 5. Control block diagram for the LPR.

For designing suitable voltage-loop proportionalintegral (PI) parameters, the key is to obtain $G_{i q_{-} d c}(s)$. Given that $i_{d L}=0$ control is applied for the surface mounted PMG, $G_{i q \_d c}(s)$ can be derived on the basis of (4) and (8)

$$
G_{i q_{-} d c}(s)=\frac{\Delta i_{d c}}{\Delta i_{q L}}=\frac{1.5\left[\bar{u}_{q}+\left(R_{s}+L_{q} s\right) \bar{i}_{q L}\right]}{\bar{v}_{d c}}+\frac{\Delta \varepsilon_{q}-\bar{i}_{d c} \Delta v_{d c}}{\bar{v}_{d c} \Delta i_{q}}
$$

Denote the transfer function of the PI regulator as $G_{p i}(s)$, the dc current dynamics from $\Delta i_{d c}{ }^{r e f}$ to $\Delta i_{d c}$ can be derived as follows:

$$
G_{i d c}(s)=\frac{\Delta i_{d c}}{\Delta i_{d c} r e f}=\frac{G_{p i}(s) G_{c}(s) G_{i q_{-} d c}(s)}{1+G_{p i}(s) G_{c}(s) G_{i q_{-} d c}(s)}
$$

Given that the dynamics of the outer voltage-loop is slower than that of the inner current-loop, the term $\left(\Delta \varepsilon_{q}-\bar{i}_{d c} \Delta v_{d c}\right) / \bar{v}_{d c} \Delta i_{q}$ in (9) can be regarded as a disturbance with slow dynamics. Applying (9) into (10), $G_{i d c}(s)$ can be derived as follows, where $k_{p}$ and $k_{i}$ are the PI parameters of the dc current controller.

$$
\begin{aligned}
& G_{\text {idc }}(s)=\frac{a_{2} s^{2}+a_{1} s+a_{0}}{b_{2} s^{2}+b_{1} s+b_{0}} \\
& =\frac{k_{p} L_{q} \bar{i}_{q L} s^{2}+\left[k_{p}\left(\bar{u}_{q}+R_{s} \bar{i}_{q L}\right)+k_{i} L_{q} \bar{i}_{q L}\right] s+k_{i}\left(\bar{u}_{q}+R_{s} \bar{i}_{q L}\right)}{k_{p} L_{q} \bar{i}_{q L} s^{2}+\left[k_{p}\left(\bar{u}_{q}+R_{s} \bar{i}_{q L}\right)+k_{i} L_{q} \bar{i}_{q L}+\frac{2}{3} \bar{v}_{d c}\right] s+k_{i}\left(\bar{u}_{q}+R_{s} \bar{i}_{q L}\right)}
\end{aligned}
$$

The location of poles of $G_{i d c}(s)$ mainly determines its performances. To tune the controller gains, a second order system whose denominator is $s^{2}+2 \xi \omega_{n} s+\omega_{n}{ }^{2}$ is designed. $\xi$ and $\omega_{n}$ are damping ratio and natural frequency, respectively. $G_{i d c}(s)$ will be used in the next section for analyzing the stability of the HVDC grid.

Therefore, the controller parameters can be written as

$$
\left\{\begin{array}{l}
k_{p}=\frac{2 \bar{v}_{d c}}{3\left[2 \xi \omega_{n} L_{q} \bar{q}_{q L}-\left(\omega_{n} L_{q} \bar{i}_{q L}\right)^{2} /\left(\bar{u}_{q}+R_{s} \bar{i}_{q L}\right)-\left(\bar{u}_{q}+R_{s} \bar{i}_{q L}\right)\right]} \\
k_{i}=\frac{2 \bar{v}_{d c} \omega_{n}^{2} L_{q} \bar{i}_{q L}}{3\left[2 \xi \omega_{n} L_{q} \bar{i}_{q L}\left(\bar{u}_{q}+R_{s} \bar{i}_{q L}\right)-\left(\omega_{n} L_{q} \bar{i}_{q L}\right)^{2}-\left(\bar{u}_{q}+R_{s} \bar{i}_{q L}\right)^{2}\right]}
\end{array}\right.
$$

The values of natural frequency and damping ratio are presented in Appendix I. It can be seen from (12) that at different operating points (i.e., with different $\bar{v}_{d c}, \bar{l}_{q L}$, and $\bar{u}_{q}$ ), the PI parameters can be tuned adaptively to achieve a consistent performance.

Based on the dc current dynamics given in (11), a thirdorder de voltage transfer function can be derived as follows:

$$
G_{v d c}(s)=\frac{\Delta v_{d c}}{\Delta v_{d c}{ }^{\text {ref }}}=\frac{G_{i d c}(s)}{G_{i d c}(s)+k_{D}\left(C s+\frac{\bar{P}}{\overline{\bar{v}}_{d c}{ }^{2}}\right)}=\frac{z_{2} s^{2}+z_{1} s+z_{0}}{p_{3} s^{2}+p_{2} s^{2}+p_{1} s+p_{0}}
$$

where

$$
p_{3}=b_{2} k_{D} C s^{3} \quad, \quad p_{2}=a_{2}+\frac{b_{2} k_{D} \bar{P}}{\bar{v}_{d c}{ }^{2}}+b_{1} k_{D} C \quad,
$$

$p_{1}=a_{1}+\frac{b_{1} k_{D} \bar{P}}{\bar{v}_{d c}{ }^{2}}+b_{0} k_{D} C, p_{0}=a_{0}+\frac{b_{0} k_{D} \bar{P}}{\bar{v}_{d c}{ }^{2}}, z_{2}=a_{2}, z_{1}=a_{1}, z_{0}=a_{0}$.

Details of $a_{2}, a_{1}, a_{0}, b_{2}, b_{1}$, and $b_{0}$ can be found in (11).

The magnitude of $G_{v d c}(s)$ is plotted at various load powers as shown in Fig. 6. Parameters of the electrical machine and operating points are presented in Appendix I. Following information can be obtained from Fig. 6:

1) As the increase of load power from $5 \mathrm{~kW}$ to $25 \mathrm{~kW}$, the magnitude becomes smaller. This is because as the increase of power, the dc current also increases. According to (1), this means a larger deviation between 
the actual dc bus voltage and reference. Therefore, the magnitude in Bode diagram will decline.

2) At $100 \mathrm{~Hz}$, the magnitude damps around $3 \mathrm{~dB}$ compared with the original value in the low-frequency region. This is consistent with the desinged bandwidth. It means the adaptive parameters in (12) can ensure a constant bandwidth for controlling the de voltage.

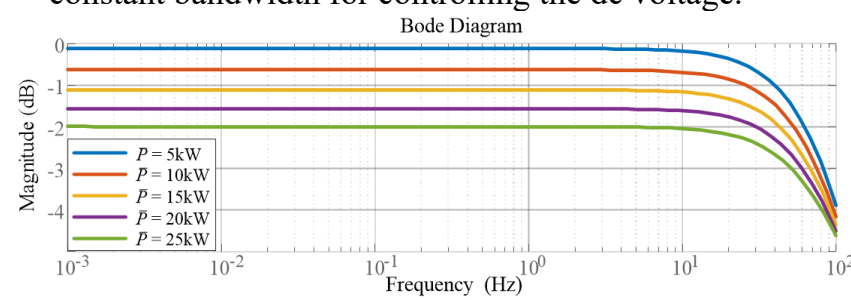

Fig. 6. Bode plot of the de voltage transfer function shown in (13).

\section{DC GRID STABILITY ANALYSIS WITH DIFFERENT POWER SHARING RATIOS BETWEEN THE HPR AND LPR}

To analyze the HVDC grid stability with different power sharing ratios between the HPR and the LPR, a dc side equivalent circuit is built as shown in Fig. 7, including the droop-controlled rectifiers, cables, dc capacitors, and loads. The superscripts $H P$ and $L P$ represent the variables of the HP and LP power generation channel, respectively. Since a current mode droop control is implemented (see (1)), the HP and LP channel can be regarded as current sources. In Fig. 7, $i_{d c}{ }^{H P}$ and $i_{d c}{ }^{L P}$ are current sources controlled by the local dc voltages $v_{d c}{ }^{H P}$ and $v_{d c}{ }^{L P}$, and the droop gains $k_{D}{ }^{H P}$ and $k_{D}{ }^{L P}$. The de current dynamics $G_{i d c}(s)$ derived in (11) is also considered. The dc currents can be expressed as follows:

$$
i_{d c}^{H P}=\frac{v_{d c}^{r e f}-v_{d c}{ }^{H P}}{k_{D}^{H P}} G_{i d c}^{H P}(s) \quad i_{d c}{ }_{d c}^{L P}=\frac{v_{d c}{ }^{r e f}-v_{d c}{ }^{L P}}{k_{D}{ }^{L P}} G_{i d c}{ }^{L P}(s)
$$

In Fig. 7, $C_{H P}$ and $C_{L P}$ are the capacitances of the local dc capacitors. The transmission cables are represented by $R L$ branches and their admittances are denoted as $X_{H P}$ and $X_{L P}$, respectively. $v_{m b}$ and $C_{m b}$ are the voltage and capacitor of the global main HVDC bus.

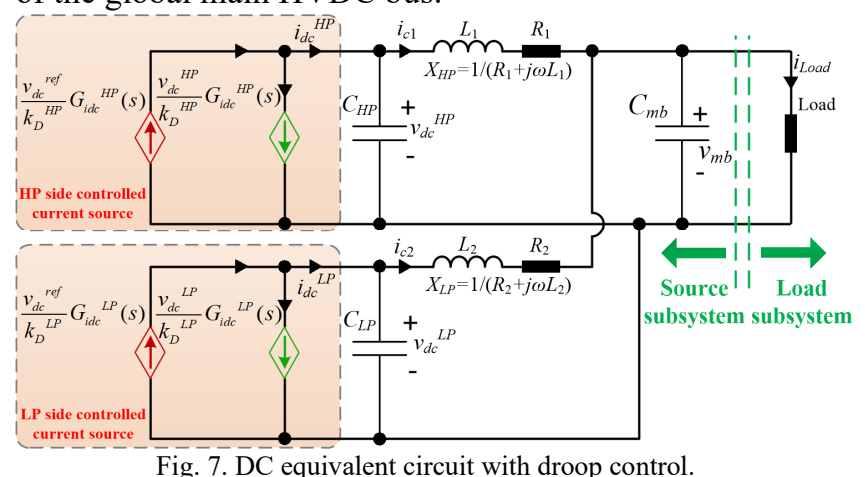

\section{A. Impedance Based Stability Analysis Using Middlebrook Criterion}

Middlebrook proposed an impedance-based approach to analyze stability, which allows definition of stability criterion for every individual subsystem through convenient impedance specifications [18]. Considering the magnitude of impedances of source and load subsystems as $\left\|Z_{s}\right\|$ and $\left\|Z_{L}\right\|$, respectively, the Middlebrook Criterion gives a sufficient stability condition, which is:

$$
\left\|Z_{s}\right\| \ll\left\|Z_{L}\right\|
$$

From (15) it shows that the system stability can be assessed by $\left\|Z_{s}\right\|$. To obtain $\left\|Z_{s}\right\|$, the open-circuit voltage $v_{o c}(s)$ and short-circuit current $i_{s c}(s)$ of the source subsystem in Fig. 7 in Laplace domain are derived as follows. The derivation process is given in Appendix II.

$$
\left\{\begin{array}{c}
v_{o c}(s)=\frac{\sum_{j=L P}^{H P} \frac{X_{j} G_{i d c}{ }^{j}}{s C_{j} k_{D}{ }^{j}+k_{D}{ }^{j} X_{j}+G_{i d c}{ }^{j}} v_{d c}{ }^{r e f}}{s C_{m b}+\sum_{j=L P}^{H P} \frac{s C_{j} k_{D}{ }^{j} X_{j}+G_{i d c}{ }^{j} X_{j}}{s C_{j} k_{D}{ }^{j}+k_{D}{ }^{j} X_{j}+G_{i d c}{ }^{j}}} \\
i_{s c}(s)=\sum_{j=L P}^{H P} \frac{X_{j} G_{i_{d i c}}{ }^{j}}{s C_{j} k_{D}{ }^{j}+k_{D}{ }^{j} X_{j}+G_{i d c}{ }^{j}} v_{d c}{ }^{r e f}
\end{array}\right.
$$

Therefore, the output impedance of the source subsystem can be derived as follows:

$$
Z_{s}(s)=\frac{v_{o c}(s)}{v_{o c}(s)}=\frac{1}{s C_{m b}+\sum_{j=L P}^{H P} \frac{s C_{j} k_{D}{ }^{j} X_{j}+G_{i d c}{ }^{j} k_{j}{ }^{j}+k_{D}{ }^{j} X_{j}+G_{i d c}{ }^{j}}{s}}
$$

Fig. 8 presents the Bode plot of the impedance $Z_{s}(s)$, where the system parameters are given in Appendix III. It can be seen that as the proportion of the LPR's power increases, the peak magnitude of the source impedance at the low-frequency region will decrease. According to the Middlebrook Criterion, reduction in the magnitude of the source subsystem impedance indicates that the system tends to be more stable [19], [20].

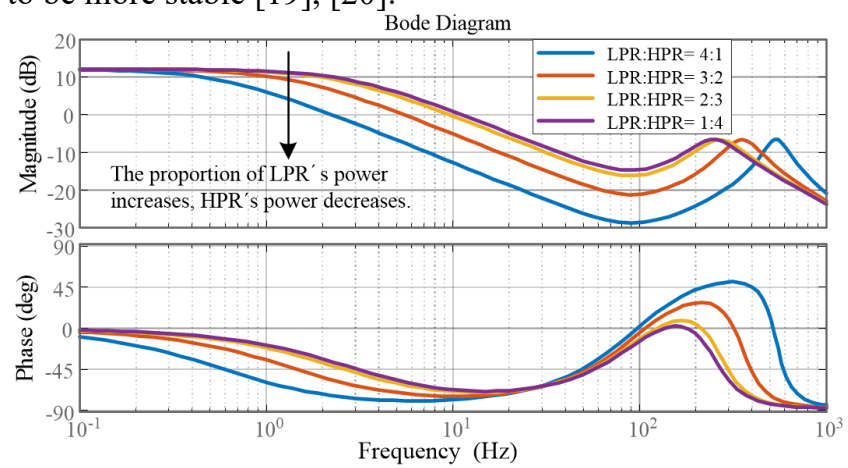

Fig. 8. Bode plot of source impedance $\left\|Z_{s}(s)\right\|$ in (17) at different power sharing ratios between the LPR and HPR.

\section{B. Time Domain Analysis Using State-Space Model}

In order to verify the impedance analysis results in the above subsection, in this subsection the equivalent circuit shown in Fig. 7 is further analyzed using a state-space model. Then the outcomes of the state-space model and the impedance model are compared to see whether they are consistent.

The currents of inductors and voltages across capacitors are selected as state variables. Then the state-space model can be expressed as follows:

$$
\Delta \dot{x}=A \Delta x
$$

where $x=\left[v_{d c}^{H P}, v_{d c}{ }^{L P}, i_{c 1}, i_{c 2}, v_{m b}\right] . A$ is the system matrix.

Considering the droop control effect in (1), $v_{d c}{ }^{L P}$ can be written as

$$
v_{d c}^{L P}(s)=\left[v_{d c}^{r e f}(s)-k_{D}{ }^{L P} i_{d c}{ }^{L P}(s)\right] G_{v d c}{ }^{L P}(s)
$$

where $G_{v d c}{ }^{L P}(s)$ is the dc voltage transfer function of the LPR control system which has been expressed in (13).

The original $G_{v d c}{ }^{L P}(s)$ as shown in (13) is a third-order 
transfer function, which will complicate the state-space model. Properly order reduction is required. Substitute the $s$ with $j \omega, G_{v d c}{ }^{L P}(s)$ can be transformed from the Laplace domain to the frequency domain, shown as follows:

$$
\begin{aligned}
G_{v d c}{ }^{L P}(j \omega) & =\frac{z_{2}(j \omega)^{2}+z_{1}(j \omega)+z_{0}}{p_{3}(j \omega)^{3}+p_{2}(j \omega)^{2}+p_{1}(j \omega)+p_{0}} \\
& =\frac{z_{1}(j \omega)+\left(z_{0}-z_{2} \omega^{2}\right)}{\left(p_{1}-p_{3} \omega^{2}\right) j \omega+\left(p_{0}-p_{2} \omega^{2}\right)}
\end{aligned}
$$

As shown in Appendix III, the control bandwidth for the dc voltage is designed as $100 \mathrm{~Hz}$. Hence, the frequency range from $0 \mathrm{~Hz}(\omega=0 \mathrm{rad} / \mathrm{s})$ to $150 \mathrm{~Hz}(\omega=942.5 \mathrm{rad} / \mathrm{s})$ which covers the control bandwidth is focused to investigate the characteristic of $G_{v d c}{ }^{L P}(j \omega)$ in (20). For the studied system whose parameters are given in Appendix I and III, when the frequency component $\omega$ is within the range of interest $[0,942.5 \mathrm{rad} / \mathrm{s}]$, the following relations are met:

$$
z_{2} \omega^{2} \ll \frac{z_{0}}{10} \quad p_{3} \omega^{2} \ll \frac{p_{1}}{10} \quad p_{2} \omega^{2} \ll \frac{p_{0}}{10}
$$

Therefore, $G_{v d c}{ }^{L P}(j \omega)$ in (20) can be simplified as follows:

$$
G_{v d c}^{L P} \text { simp }(j \omega) \approx \frac{z_{1}(j \omega)+z_{0}}{p_{1}(j \omega)+p_{0}}
$$

To validate the order reduction, the magnitude and phase characteristics of the original $G_{v d c}{ }^{L P}(j \omega)$ in (20) and the simplified $G_{v d c}{ }^{L P} \operatorname{simp}(j \omega)$ in (22) are demonstrated in Fig. 9. It can be seen that within the control bandwidth, the magnitude and phase of the original $G_{v d c}{ }^{L P}(j \omega)$ and the simplified $G_{v d c}{ }^{L P}$ simp $(j \omega)$ are very similar. Therefore, in the frequency region that we are interested, i.e., within the bandwidth, the $G_{v d c}{ }^{L P}(j \omega)$ in (20) can be replaced by the $G_{v d c}{ }^{L P} \operatorname{simp}(j \omega)$ in (22) with a sufficient accuracy and a much lower complexity.

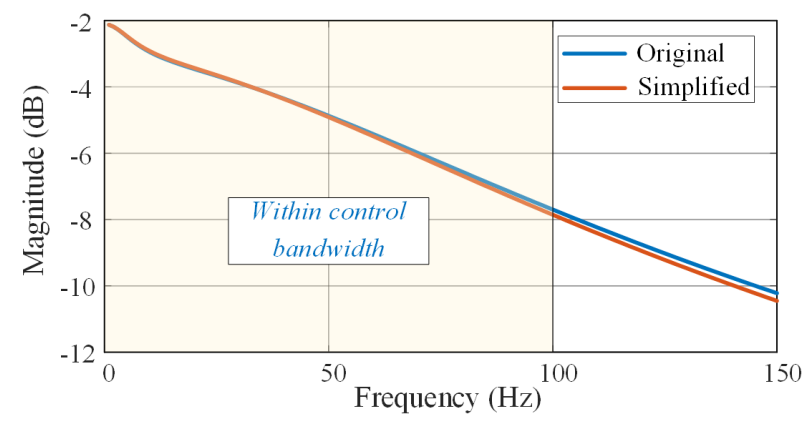

(a)

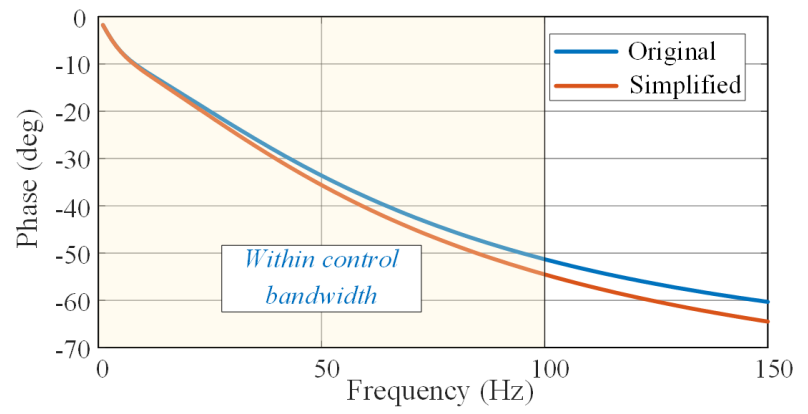

(b)

Fig. 9. The magnitude and phase characteristic of the original $G_{v d c}{ }^{L P}(j \omega)$ in (20) and the simplified $G_{v d c}{ }^{L P}(j \omega)$ in (22). (a) the magnitude characteristic. (b) the phase characteristic.

Substitute the $j \omega$ in (22) with $s$, a simplified first-order transfer function $G_{v d c}{ }^{L P}{ }_{s i m p}(s)$ can be obtained:

$$
G_{v d c}^{L P}{ }_{\text {simp }}(s) \approx \frac{z_{1} s+z_{0}}{p_{1} s+p_{0}}
$$

Apply the simplified transfer function $G_{v d c}{ }^{L P}$ simp $(s)$ in (23) to (19) and transform (19) into time domain, the following relation can be derived in the small-signal manner:

$$
\Delta \dot{v}_{d c}{ }^{L P}=-\frac{p_{0}}{p_{1}} \Delta v_{d c}{ }^{L P}-\frac{z_{0} k_{D}{ }^{L P}}{p_{1}} \Delta i_{d c}{ }^{L P}-\frac{z_{1} k_{D}{ }^{L P}}{p_{1}} \Delta \dot{i}_{d c}{ }^{L P}
$$

where the term $\Delta v_{d c}{ }^{\text {ref }}$ is omitted since $v_{d c}{ }^{\text {ref }}$ is set as a fixed 270VDC as per the MILSTD-704F standard [21].

The voltage balance equation across the transmission cable can be expressed as follows:

$$
v_{d c}^{L P}-v_{m b}=R_{2} i_{c 2}+L_{2} \frac{d i_{c 2}}{d t}
$$

where $R_{2}$ and $L_{2}$ are the equivalent resistance and inductance of the LP channel's cable, i.e., $X_{L P}=1 /\left(R_{2}+j \omega L_{2}\right)$.

Hence, the state-space equation of $i_{c 2}$ in the small signal manner can be derived as follows:

$$
\Delta i_{c 2}=\frac{1}{L_{2}} \Delta v_{d c}^{L P}-\frac{R_{2}}{L_{2}} \Delta i_{c 2}-\frac{1}{L_{2}} \Delta v_{m b}
$$

The voltage equation of the main dc capacitor is

$$
i_{c 1}+i_{c 2}=C_{m b} \frac{d v_{m b}}{d t}+i_{\text {Load }}
$$

In MEA many energy consuming loads, such as the thermal mats for wing ice protection system and the power converter driven compressors for environment control system, can be regarded as the constant impedance load (CIL) and the constant power load (CPL), respectively [22]. Hence, in this paper the system is configured with a CPL, whose power is $P_{C P L}$, and a CIL, whose impedance is $R_{C I L}$. The current of load $i_{\text {Load }}$ can be derived as follows:

$$
i_{\text {Load }}=\frac{P_{C P L}}{v_{m b}}+\frac{v_{m b}}{R_{C L}}
$$

Combing (27) and (28), the state-space equation of $v_{m b}$ in the small signal manner can be written as follows:

$$
\Delta \dot{v}_{m b}=\frac{1}{C_{m b}} \Delta i_{c 1}+\frac{1}{C_{m b}} \Delta i_{c 2}+\left(\frac{P_{C P L}}{C_{m b} \bar{v}_{m b}{ }^{2}}-\frac{1}{C_{m b} R_{C L}}\right) \Delta v_{m b}
$$

where $\bar{v}_{m b}$ is the steady operating point of the main dc bus voltage.

With (24), (26) and (29), and considering the LP and HP channels are identical as shown in Fig. 7, the system matrix $A$ in equation (18) can be derived as follows:

$$
A=\left[\begin{array}{ccccc}
-\frac{p_{0}{ }^{H P}}{p_{1}{ }^{H P}} & 0 & -\frac{z_{0}{ }^{H P} k_{D}{ }^{H P}}{p_{1}^{H P}} & 0 & 0 \\
0 & -\frac{p_{0}^{L P}}{p_{1}^{L P}} & 0 & -\frac{z_{0}^{L P} k_{D}{ }^{L P}}{p_{1}^{L P}} & 0 \\
\frac{1}{L_{1}} & 0 & -\frac{R_{1}}{L_{1}} & 0 & -\frac{1}{L_{1}} \\
0 & \frac{1}{L_{2}} & 0 & -\frac{R_{2}}{L_{2}} & -\frac{1}{L_{2}} \\
0 & 0 & \frac{1}{C_{m b}} & \frac{1}{C_{m b}} & \frac{1}{C_{m b}}\left(\frac{P_{C P L}}{\bar{v}_{m b}{ }^{2}}-\frac{1}{R_{C L L}}\right)
\end{array}\right]
$$

The matrix (30) shows the system matrix $A$ of the fifthorder state-space model in (18). Stability of the system can be assessed using the eigenvalues of $A$. Fig. 10 shows the eigenvalues loci when the power ratio between the LPR and 
the HPR changes from $0.5: 1$ to $2: 1$. It can be seen that as the LPR accounts for more power, the dominant eigenvalues will move far away from the right half-plane. It reveals that the system tends to be more stable.

The results in Fig. 8 derived from the Middlebrook approach and Fig. 10 derived from the state-space model are aligned, both indicating that increasing the proportion of the LPR's output power will contribute to a more stable $H V D C$ gird. This crucial conclusion will be further validated in Section IV and $\mathrm{V}$ through simulation and experiments. It can also be used as a criterion for researchers and engineers when designing onboard power generation centers with a sufficient stability margin for MEA application.

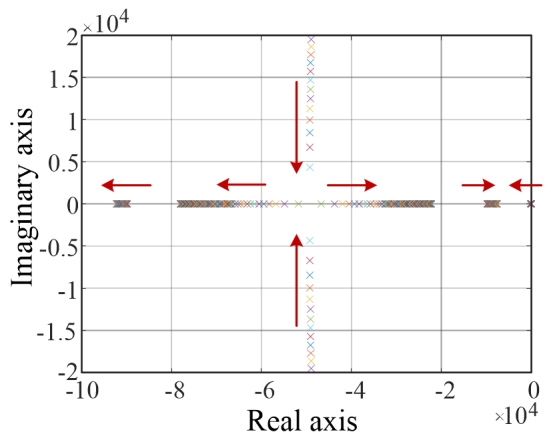

(a)

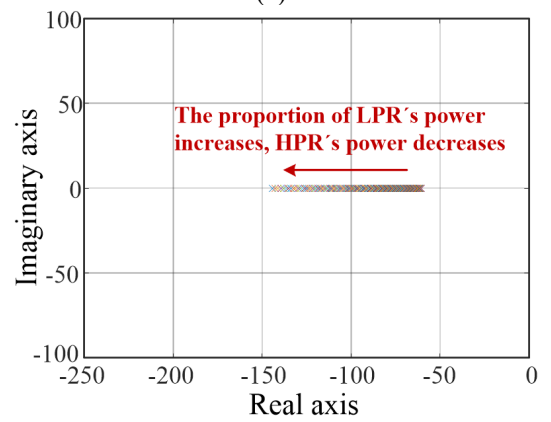

(b)

Fig. 10. Eigenvalues of the dc equivalent circuit with the variation of power sharing ratio between the HPR and the LPR. (a) Overall plot. (b) Zoomed area of the dominant eigenvalues. The arrows represent the direction that the proportion of the LPR's power increases.

\section{Influence of the Power Sharing Ratio on the Line \\ Losses}

The above stability analysis reveals the relation between the LPR's power and the HVDC grid stability, but it does not specify the HPR/LPR power ratio. To find the power sharing ratio range quantitively, other approaches or optimization objectives should be considered. In this subsection, the impact of power sharing ratio on the transmission line losses is analyzed, and the optimal power ratio is derived for minimizing the line losses.

Assume that $n_{1}$ and $n_{2}$ are the ratios of the dc side current of the HPR and the LPR to the total load current. The current sharing ratio can be expressed as

$$
\left\{\begin{array}{l}
\frac{i_{d c}{ }^{H P}}{i_{d c}{ }^{L P}}=\frac{n_{1} \cdot i_{\text {Load }}}{n_{2} \cdot i_{\text {Load }}}=\frac{n_{1}}{n_{2}} \\
\text { s.t. } n_{1}+n_{2}=1
\end{array}\right.
$$

Typically, the geometry of power system onboard MEA is symmetrical. Hence, the cable length can be assumed to be identical for HP and LP channels. Denoting the cable resistance $R_{1}$ and $R_{2}$ in Fig. 7 both as $R_{c}$, the minimization problem of line losses $\left(P_{\text {Loss }}\right)$ can be formulated as

$$
\left\{\begin{array}{l}
\min \left(P_{\text {Loss }}\right)=\min \left[\left(n_{1}^{2}+n_{2}^{2}\right) \cdot i_{\text {Load }}{ }^{2} R_{c}\right] \\
\text { s.t. } n_{1}+n_{2}=1
\end{array}\right.
$$

The Lagrange multiplier is applied to obtain the solution for (32), yielding

$$
H\left(n_{1}, n_{2}, \lambda\right)=\left(n_{1}^{2}+n_{2}^{2}\right) \cdot i_{\text {Load }}^{2} R_{c}+\lambda\left(n_{1}+n_{2}-1\right)
$$

The partial derivative of (33) is expressed as follows:

$$
\left\{\begin{array}{l}
\frac{\partial H\left(n_{1}, n_{2}, \lambda\right)}{\partial n_{1}}=2 i_{\text {Load }}{ }^{2} R_{c} n_{1}+\lambda=0 \\
\frac{\partial H\left(n_{1}, n_{2}, \lambda\right)}{\partial n_{2}}=2 i_{\text {Load }}{ }^{2} R_{c} n_{2}+\lambda=0 \\
\frac{\partial H\left(n_{1}, n_{2}, \lambda\right)}{\partial \lambda}=\left(n_{1}+n_{2}-1\right)=0
\end{array}\right.
$$

Eliminating the parameter $\lambda$ in (34), the optimal power sharing ratio aiming for line losses minimization can be obtained as follows:

$$
\frac{n_{1}}{n_{2}}=\frac{k_{D}{ }^{L P}}{k_{D}{ }^{H P}}=1
$$

\section{Power Decoupling Characteristic of the APGC}

The relation in (35) presents that the LPR and the HPR shares equivalent power can minimize the line losses. The findings in Fig. 8 and Fig. 10 reveal that increasing the proportion of the LPR's power is beneficial to the HVDC grid stability. Summarizing the above findings to achieve a trade-off, it can be concluded that the LPR should deliver more power than the HPR to enhance the HVDC grid stability and reduce the line losses.

However, given the stability of engine, in maximum take-off and top of climb modes, more mechanical power is extracted from the HPS than the LPS to avoid the overspeed of the HPS and potential instability [13], [14]. For the PGC in Fig. 1, the Power Coupling Effect makes it infeasible to extract more power from the HPS and meanwhile delivering more power to the dc bus through the LPR. However, with the APGC, the BTB converter can transfer power from the HP to LP channel, allowing the HPS shares more power than the LPS and meanwhile the LPR feeds more power than the HPR. Hence, the APGC presents a Power Decoupling characteristic.

\section{Simulation RESUlts}

To verify the analytical findings in Section III, an equivalent nonlinear MATLAB/Simulink model of the PGC shown in Fig. 1 is built to test the HVDC grid stability under different power sharing ratios between the HPR and the LPR. The system parameters are presented in Appendix III. As stated in Section III, the impedance of transmission cable of the HP and LP channels are assumed identical. The control scheme for both rectifiers has been presented in Fig. 3, where the control bandwidths for the voltage loop and current loop are $100 \mathrm{~Hz}$ and $1 \mathrm{kHz}$, respectively. The associated control parameters are also given in Appendix III. Decoupling terms and anti-windup scheme presented in [23] are used for current controller to achieve a better dynamic performance.

The dc currents and voltage under different power 
sharing ratios between the HPR and the LPR are presented in Fig. 11. Fig. 11(a) and (c) present the dc currents and voltage where the power of the LPR $\left(P_{L P R}\right)$ is triple of that of the HPR $\left(P_{H P R}\right)$, i.e., $P_{H P R}: P_{L P R}=1: 3$. It can be seen that as the increase of load power from $10 \mathrm{~kW}$ to $30 \mathrm{~kW}$, the $\mathrm{dc}$ voltage decreases due the droop control effect. The $i_{d c}{ }^{L P}$ is tighltly controlled to be thriple of $i_{d c}{ }^{H P}$ in the whole process, showing smooth performance in transient and steady states.

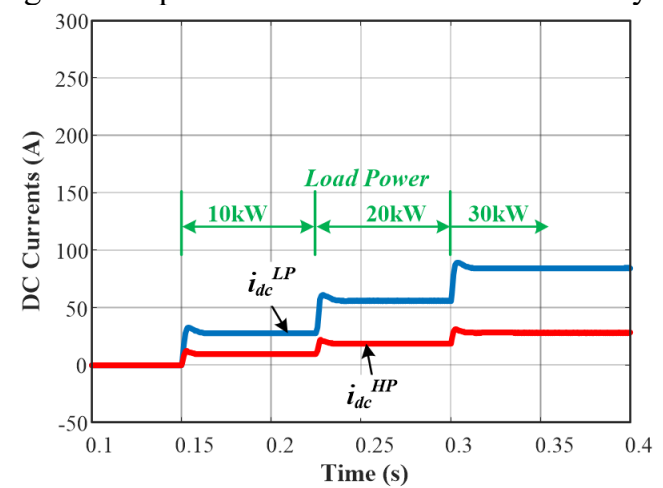

(a)

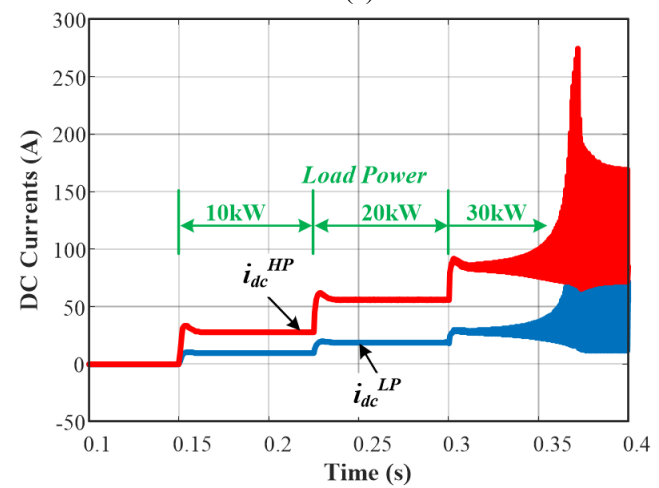

(b)

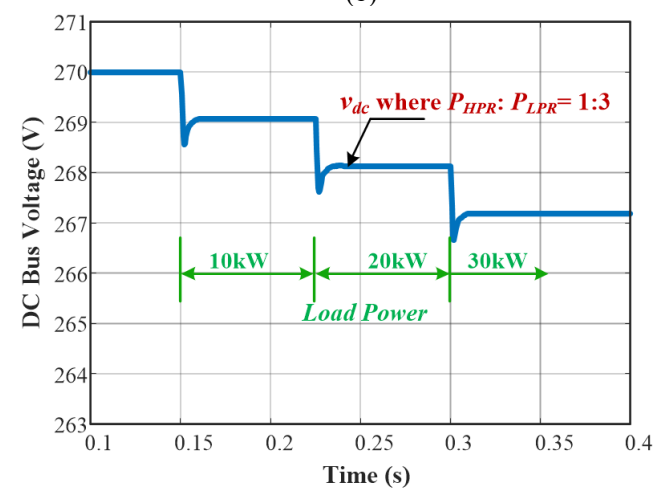

(c)

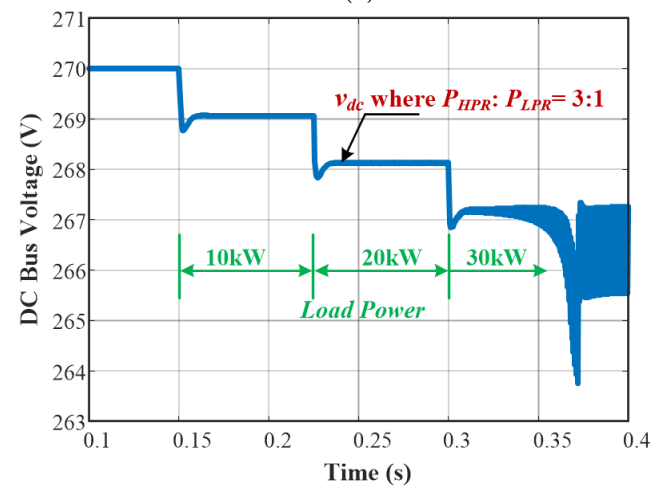

(d)

Fig. 11. Simulation results of the HVDC grid stability under different power sharing ratios between the HPR and the LPR. (a) dc currents where $P_{H P R}: P_{L P R}=1: 3$. (b) dc currents where $P_{H P R}: P_{L P R}=3: 1$. (c) Main dc voltage $v_{d c}$ where $P_{H P R}: P_{L P R}=1: 3$. (d) Main dc voltage $v_{d c}$ where $P_{H P R}$ : $P_{L P R}=3: 1$.

Swapping the power sharing ratio between the HPR and the LPR, i.e., $P_{H P R}: P_{L P R}=3: 1$, and keeping the rest of configurations unchanged, the system responses are exhibited in Fig. 11(b) and (d). With 10kW and 20kW load power, the system remains stable, same as that in Fig. 11(a) and (c). However, as the load power increases to $30 \mathrm{~kW}$, the system moves to a unstable state with severe oscillation in the dc currents and dc voltage. The comparative results in Fig. 11 show that increasing the power ratio of the LPR in the heavy load condition will contribute to a more stable HVDC grid. The simulation results are in accordance with the analytical findings in Section III-A and B.

According to the operating points in Fig. 11 and the system parameters in Appendix III, Bode plot of source and load impedances under different load powers and power sharing ratios between the HPR and the LPR are presented in Fig. 12. The expression of source impedance $Z_{s}(s)$ has been formulated in (17). A dc/dc buck converter is regulated as a CPL, whose circuitry model is presented in Appendix III. The load impedance $Z_{L}(s)$ of the buck converter can be expressed as follows [24]:

$$
Z_{L}(s)=-R_{i c} \frac{\frac{s^{2}}{\omega_{o}^{2}}+\frac{s}{Q_{0} \omega_{o}}+1}{\frac{s}{\omega_{p}}+1}
$$

where the definitions and values of $R_{i c}, \omega_{o}, \omega_{p}$ and $Q_{0}$ are given in Appendix III.

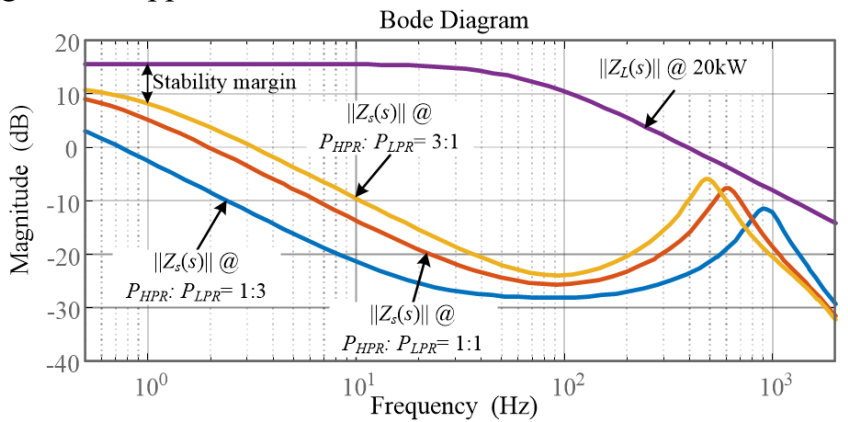

(a)

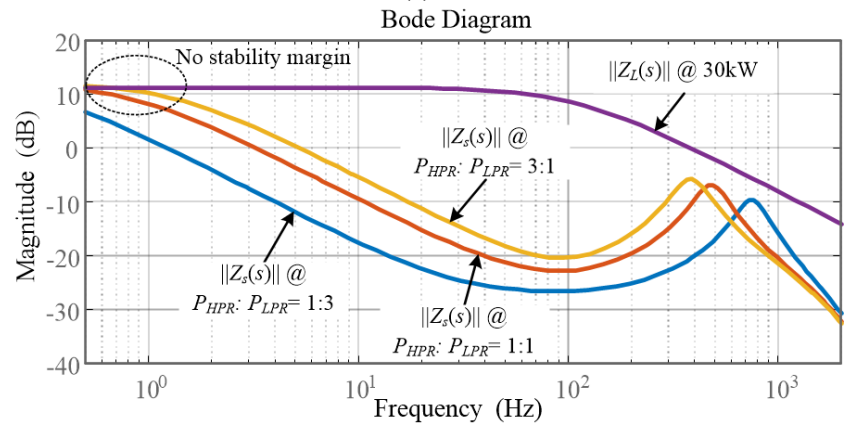

(b)

Fig. 12. Bode plot of source and load impedances under different load powers and power sharing ratios between the HPR and the LPR. (a) source and load impedances with $20 \mathrm{~kW}$ load power. (b) source and load impedances with $30 \mathrm{~kW}$ load power.

It can be seen from Fig. 12(a) that under 20kW load condition, the magnitude of $Z_{s}(s)$ at various power sharing ratios is much smaller than the magnitude of $Z_{L}(s)$. As shown in (15), according to the Middlebrook Criterion, this 
indicates a sufficient system stability margin. This result is consistent with the simulation results in Fig. 11, where the system remains stable under $20 \mathrm{~kW}$ load condition for both $P_{H P R}: P_{L P R}=1: 3$ and 3:1. However, Fig. 12(b) shows that as the load power increases to $30 \mathrm{~kW}$, the magnitude of $Z_{s}(s)$ with $P_{H P R}: P_{L P R}=3: 1$ and $1: 1$ is very close to the magnitude of $Z_{L}(s)$, showing no stability margin. This is consistent with the simulation results in Fig. 11(b) and (d), where the system becomes unstable under $30 \mathrm{~kW}$ load power condition. By decreasing the ratio $P_{H P R}: P_{L P R}$ to $1: 3$, the magnitude of $Z_{S}(s)$ decreases, meeting the requirement in (15). This is why in Fig. 11(a) and (c) where $P_{H P R}: P_{L P R}=$ $1: 3$, the system operates smoothly even though under $30 \mathrm{~kW}$ load power.

The line losses under $20 \mathrm{~kW}$ and $30 \mathrm{~kW}$ load conditions with different power sharing ratios are presented in Fig. 13. The value of cable impedance is demonstrated in Appendix III. It can be seen that a minimal line losses is achieved at $P_{H P R}: P_{L P R}=1: 1$. This is consistent with the analysis in Section III-C. The increase of line losses caused by increased power ratio of the LPR is less than $5 \mathrm{~W}$, which is trivial compared with the total load power. Hence, the HVDC grid stability should be the main consideration for designing the power ratio between the HPR and the LPR.

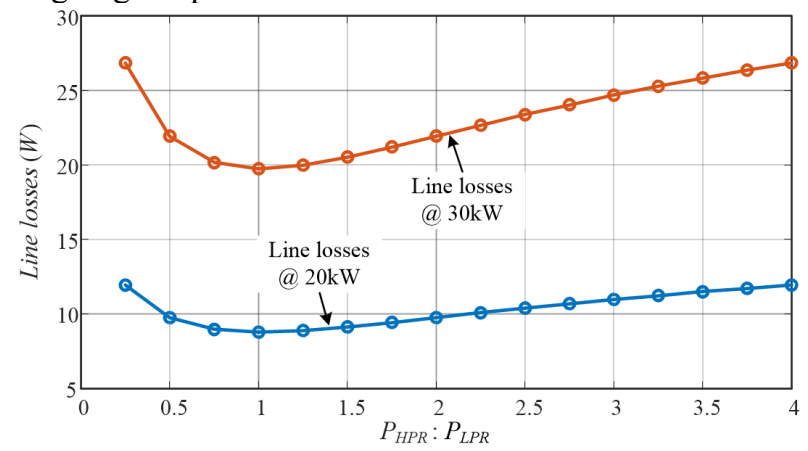

Fig. 13. Line losses under $20 \mathrm{~kW}$ and $30 \mathrm{~kW}$ load power conditions with different power sharing ratios.

\section{Validations on a Downscaled Lab Prototype}

According to the above theoretical analysis and simulation results, it can be concluded that the LPR is expected to share more power than the HPR to enhance the stability of the HVDC grid. However, in the high-power settings of engine, the HPS of engine needs to share more power than the LPS of engine to avoid overspeed of the HPS. It has been pointed out that the PGC in Fig. 1 cannot fulfill the two goals due to the Power Coupling Effect (PCE). While the APGC in Fig. 2 contains a BTB converter as a power decoupling bridge, which allows bidirectional power flow between the HP and the LP channels. Hence, the PCE is removed and the stability of HVDC grid and engine can be enhanced. To investigate this point, a downscaled lab prototype of the APGC consisting of two rectifiers and one BTB converter has been built, as shown in Fig. 14.

In Fig. 14, TMDSCNCD28379D is used as the digital control platform. A resistor bank and a dc electronic load are parallel connected to the dc bus, behaving as CIL and CPL, respectively. An autotransformer whose primary side is connected with the utility grid is used to emulate the LPG. Its electrical frequency is $50 \mathrm{~Hz}$. A Chroma 31120 programmable ac source is used to emulate the HPG, whose voltage frequency is set as $80 \mathrm{~Hz}$. The switching frequency is $5 \mathrm{kHz}$. Current loop and voltage loop execution frequencies are $5 \mathrm{kHz}$ and $1 \mathrm{kHz}$, respectively. The current and voltage control bandwidth is designed as $1 \mathrm{kHz}$ and $100 \mathrm{~Hz}$, respectively. The filter inductance is $2.5 \mathrm{mH}$. LV25$\mathrm{P}$ and LA200-P are used as voltage and current transducers.

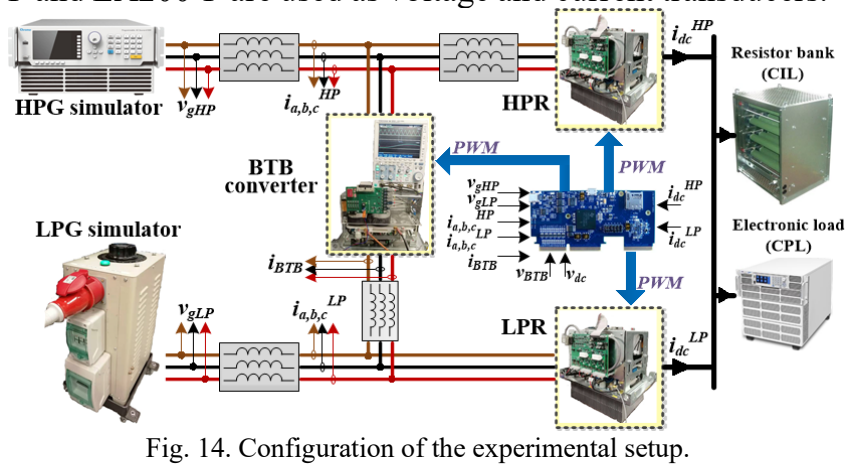

\section{A. Control Performances of the APGC}

The control scheme for rectifiers has been presented in Fig. 3. Details of control design for the BTB converter can be found in [11]. As revealed in above section, the LPR is suggested to deliver more power than the HPR. Here the power sharing ratio between the HPR and the LPR is set as 1:2, i.e., $P_{H P R}: P_{L P R}=1: 2$. To simulate the situation that extracting more mechanical power from the HPS than LPS, the ratio between the HPG's power $\left(P_{H P G}\right)$ and LPG's power $\left(P_{L P G}\right)$ is set as $2: 1$. Thus the BTB converter transfers power from the HP channel to the LP channel.

Control performance of the APGC under various load power conditions is demonstrated in Fig. 15 and Fig. 16. The whole process is divided into five stages. At stage 1 and 5 , the CPL is deactivated and only a $40 \Omega$ CIL consumes $1.8 \mathrm{~kW}$ power. At stage 2 and 4, the CPL is activated and the total load power increases to $2.5 \mathrm{~kW}$. At stage 3 , the CPL consumes more power, resulting in a $3.0 \mathrm{~kW}$ load power.

The results of $v_{d c}, i_{d c}{ }^{H P}$ and $i_{d c}{ }^{L P}$ are presented in Fig. 15. It can be seen that as the increase of load power, $v_{d c}$ deviates from the rated value $270 \mathrm{~V}$ to $263.0 \mathrm{~V}, 260.0 \mathrm{~V}$ and $258.0 \mathrm{~V}$ due to the droop control effect. $i_{d c}{ }^{L P}$ is around double of $i_{d c}{ }^{H P}$ in the whole process $(4.6 \mathrm{~A} / 2.3 \mathrm{~A}, 6.6 \mathrm{~A} / 3.3 \mathrm{~A}, 8.0 \mathrm{~A} / 4.0 \mathrm{~A})$, which means the output power of the LPR is successfully controlled to twice that of the HPR. The phase currents of the HPG, LPG and BTB $\mathrm{H}_{\mathrm{H}}$ converter are exhibited in Fig. 16. It can be seen that as the increase of load power, the phase currents of the HPG and the LPG increase as they need to supply more power. The phase current of the $\mathrm{BTB}_{\mathrm{H}}$ converter also increase because the BTB converter transfers more power from the HP to the LP channel. It should be noted that the phase current of the LPG distorts, this is due to the inherent distortion of the utility grid voltage. Based on the above-mentioned power sharing ratios, the relationships of power flow at different stages are summarized in Table I.

To verify the values of power flow in Table $\mathbf{I}$, the operating status of the HPG simulator is recorded as shown in Fig. 17. As shown in Table I, ideally the power of the HPG emulator $\left(P_{H P G}\right)$ should be $1.67 \mathrm{~kW}$ and $2.00 \mathrm{~kW}$ at stage 2 and 3, respectively. The actual results in Fig. 17 are $1.78 \mathrm{~kW}$ and $2.10 \mathrm{~kW}$, which are well matched with the ideal values considering the inevitable power losses. This confirms the power control performance. 
Table I. Relationships of power flow at different operating stages

\begin{tabular}{c|c|c|c|c|c|c}
\hline & $\begin{array}{c}\text { Total load } \\
\text { power }\end{array}$ & $\begin{array}{c}\text { Output power of } \\
\text { the HPR }\left(P_{H P R}\right)\end{array}$ & $\begin{array}{c}\text { Output power of } \\
\text { the LPR }\left(P_{L P R}\right)\end{array}$ & $\begin{array}{c}\text { Extracted power from } \\
\text { the HPS }\left(P_{H P G}\right)\end{array}$ & $\begin{array}{c}\text { Extracted power from } \\
\text { the LPS }\left(P_{L P G}\right)\end{array}$ & $\begin{array}{c}\text { Transferred power through } \\
\text { the BTB converter }\end{array}$ \\
\hline $\begin{array}{c}\text { Stage } 1 \\
\& 5\end{array}$ & $1.8 \mathrm{~kW}$ & $0.6 \mathrm{~kW}$ & $\frac{1}{3} P_{t}$ & $\frac{1}{3} P_{t}$ & $\frac{1}{3} P_{t}$ & $P_{H P G}-P_{H P R}=\frac{1}{3} P_{t}$ \\
\hline $\begin{array}{c}\text { Stage } 2 \\
\& 4\end{array}$ & $2.5 \mathrm{~kW}$ & $0.83 \mathrm{~kW}$ & $1.2 \mathrm{~kW}$ & $1.2 \mathrm{~kW}$ & $0.6 \mathrm{~kW}$ & $0.6 \mathrm{~kW}$ \\
\hline Stage 3 & $3.0 \mathrm{~kW}$ & $1.0 \mathrm{~kW}$ & $2.0 \mathrm{~kW}$ & $1.67 \mathrm{~kW}$ & $0.83 \mathrm{~kW}$ & $0.83 \mathrm{~kW}$ \\
\hline \hline
\end{tabular}

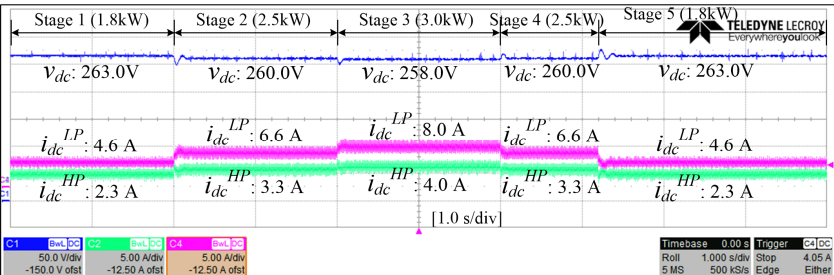

Fig. 15. The dc voltage and currents with $1.8 \mathrm{~kW}, 2.5 \mathrm{~kW}$ and $3.0 \mathrm{~kW}$ load powers.

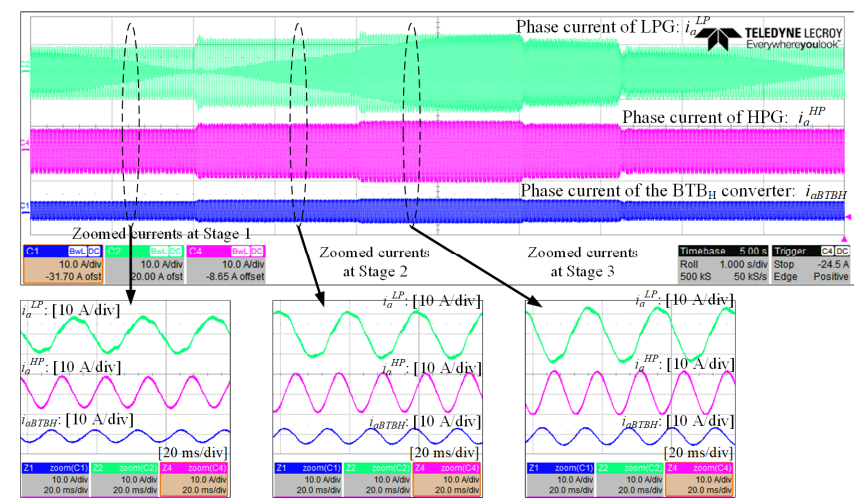

Fig. 16. Phase currents of the HPG, the LPG and the $\mathrm{BTB}_{\mathrm{H}}$ converter.

From the results from Fig. 15 to Fig. 17, it can be seen that using the APGC, the LPR can feed more power than the HPR to the dc bus, meanwhile more mechanical power can be extracted from the HPS than the LPS by controlling their associated generators. Hence, the inherent Power Coupling defect of the PGC can be removed using the APGC by transferring power from the HP channel to the LP channel through the BTB converter.

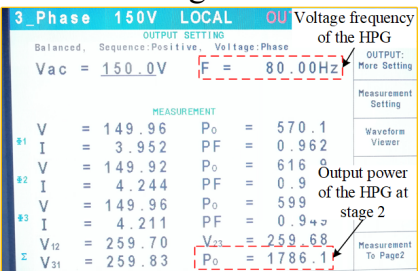

(a)

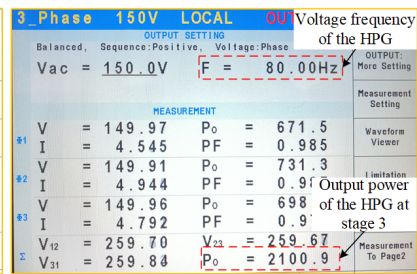

(b)
Fig. 17. Output power of the HPG simulator at (a) Stage 2. (b) Stage 3.

\section{B. Investigation of HVDC Grid Stability with Different Power Sharing Ratios Between the HPR and LPR}

In this subsection, the impact of power sharing ratio between the HPR and LPR on the HVDC grid stability is examined. Firstly, an equivalent simulation model as the lab prototype in Fig. 15 is built. The simulation results are exhibited in Fig. 18, where the dc bus voltage $v_{d c}$, dc currents of the HPR and LPR $\left(i_{d c}{ }^{H P}\right.$ and $\left.i_{d c}{ }^{L P}\right)$ are shown. From $1 \mathrm{~s}-2 \mathrm{~s}$, the power ratio between the LPR and HPR is 2:1, i.e., $P_{L P R}: P_{H P R}=2: 1$. Subsequently, the power ratio between the LPR and HPR gradually decreases to $1: 2$, i.e., $P_{L P R}: P_{H P R}=1: 2$. It can be seen that in this case, the system tends to be unstable with severe oscillation in the dc currents and dc voltage. Then from $4 s-5 s$, the power sharing ratio between the LPR and HPR restores to $2: 1$, the system becomes stable again.

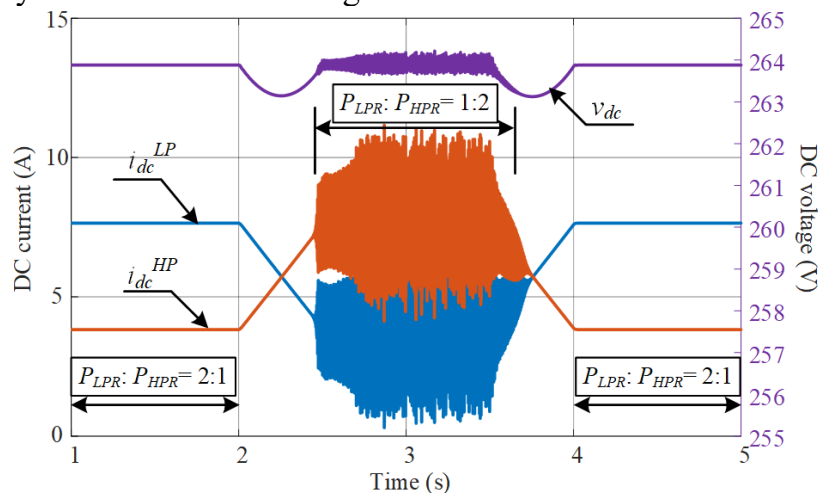

Fig. 18. Simulation results for different power sharing ratios between the HPR and LPR under $3.0 \mathrm{~kW}$ load power.

The operating points shown in Fig. 18 are used to feed the source and load impedances in (17) and (36), and the magnitude of their impedances are shown in Fig. 19. It can be seen that when $P_{L P R}: P_{H P R}=2: 1$, the source impedance $\left\|Z_{s}(s)\right\|$ is covered by the load impedance $\left\|Z_{L}(s)\right\|$ with around $6 \mathrm{~dB}$ stability margin in the low frequency region. This indicates that the system can operate in a stable state, which matches with the results in Fig. 18 from 1s - 2s and $4 \mathrm{~s}-5 \mathrm{~s}$. However, when the power ratio changes to $P_{L P R}$ : $P_{H P R}=1: 2$, in the low frequency area shown by the red dashed rectangular, $\left\|Z_{s}(s)\right\| \approx\left\|Z_{L}(s)\right\|$, showing no stability margin. Therefore, this explains why the dc voltage and currents become distorted in Fig. 18 when $P_{L P R}: P_{H P R}=1: 2$.

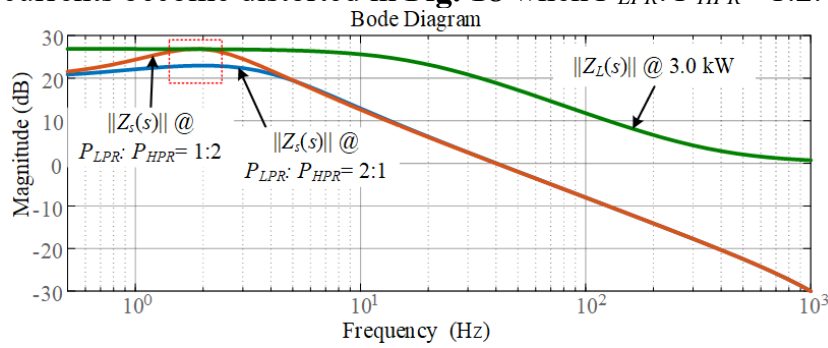

Fig. 19. Bode plot of source and load impedances with different power sharing ratios under $3.0 \mathrm{~kW}$ load power.

To further verify the simulation and analytical results in Fig. 18 and Fig. 19, experimental validations are conducted and results are shown in Fig. 20, where the dc bus voltage $v_{d c}, \mathrm{dc}$ currents of the HPR and LPR $\left(i_{d c}{ }^{H P}\right.$ and $\left.i_{d c}{ }^{L P}\right)$, and the phase current of the HPG $\left(i_{a}{ }^{H P}\right)$ are presented. Load power is also set to be $3.0 \mathrm{~kW}$ with the CPL.

Initially, the power ratio between the LPR and HPR is $2: 1$, i.e., $P_{L P R}: P_{H P R}=2: 1$. It can be seen that the system is stable. Subsequently, the power ratio between the LPR and HPR gradually decreases to $1: 2$, i.e., $P_{L P R}: P_{H P R}=1: 2$. It can 
be seen that in this case, the system loses stability with noticeable oscillation in the dc currents. Then the power sharing ratio between the LPR and HPR gradually restores to $2: 1$, the system becomes stable again.

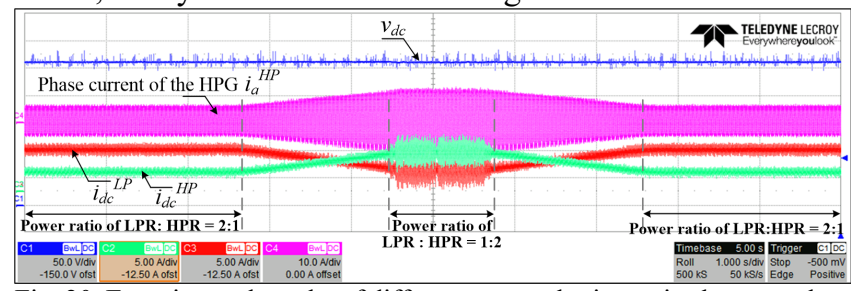

Fig. 20. Experimental results of different power sharing ratios between the HPR and LPR under $3.0 \mathrm{~kW}$ load power.

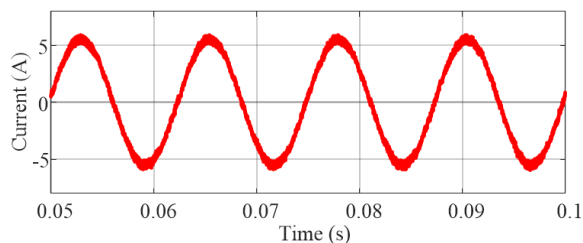

(a)

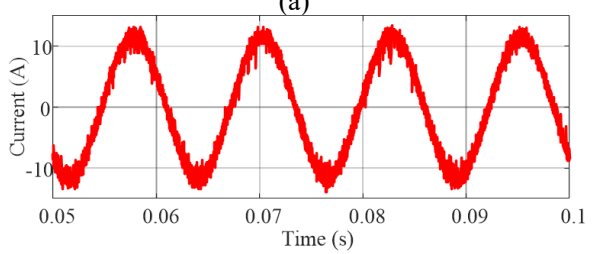

(b)
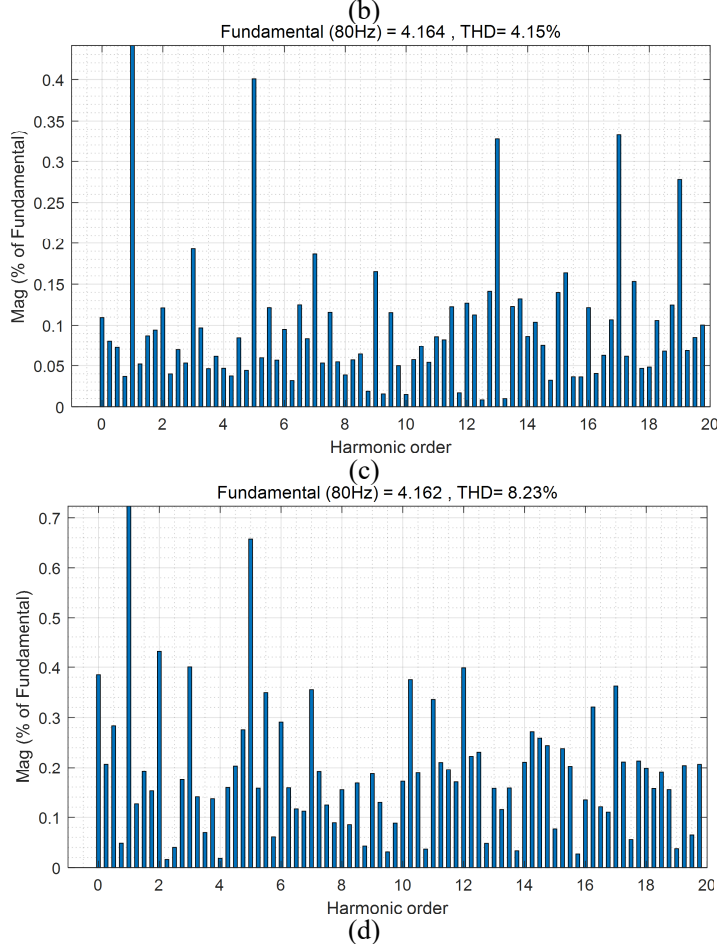

Fig. 21. Wave spectrum of the phase current of the HPG with different power sharing ratios. (a) A-phase current of the HPG when $P_{L P R}: P_{H P R}=$ $2: 1$. (b) A-phase current of the HPG when $P_{L P R}: P_{H P R}=1: 2$. (c) Harmonic spectrum of $a$-phase current of the HPG when $P_{L P R}: P_{H P R}=2: 1$. (d) Harmonic spectrum of $a$-phase current of the HPG when $P_{L P R}: P_{H P R}=1: 2$.

To quantitively analyze the system performance with different power sharing ratios, harmonic analysis of the $a$ phase current of the HPG $\left(i_{a}{ }^{H P}\right)$ is shown in Fig. 21. From Fig. 21(c) and (d) it can be seen that the total harmonic distortion (THD) of $i_{a}^{H P}$ is $4.15 \%$ when $P_{L P R}: P_{H P R}=2: 1$, while it increases to $8.23 \%$ when $P_{L P R}: P_{H P R}=1: 2$. It shows that the LPR shares more power than the HPR can improve system performance with a reduced current ripple.

To conclude this subsection, the experimental results in Fig. 20 are perfectly consistent with the simulation results in Fig. 18 and the impedance analysis in Fig. 19, confirming that increasing the proportion of the LPR's power, and make the LPR share more power than the HPR, can contribute to a more stable HVDC grid.

\section{Analysis of Engine Performance with Different \\ Power Sharing Ratios}

To study the engine performance with different power sharing ratios between the HPS and LPS, a multi-spool turbofan model is developed using the intercomponent volume method and CFM56-3 engine generic maps [13], [14]. The maximum take-off (MTO) mode is focused as an example of high-power settings of engine. Results are exhibited in Fig. 22.

Fig. 22(a) presents the HPC map and operating points with different power sharing ratios. It can be seen that when the power extracted from the LPS $\left(P_{L P S}\right)$ is double than that of the HPS $\left(P_{H P S}\right)$, i.e., $P_{L P S}=2 P_{H P S}$, the speed of the HPS exceeds the maximum allowable speed $\left(\mathrm{N}_{2}=1\right.$, where $\mathrm{N}_{2}$ is an indicator in a cockpit gauge which presents the rotational speed of the HPS). Conventionally, to decrease the speed of the HPS, pilot needs to decrease the engine throttle. While with modern multi-generator topology within a more electric engine, overspeed of the HPS can be addressed by changing the power sharing ratios between the HPS and the LPS. In Fig. 22(a), when $P_{H P S}=2 P_{L P S}$, i.e., extracting more mechanical power from the HPS than the LPS, air mass flow and pressure ratio decrease back to the allowable region within $\mathrm{N}_{2}=1$. And the operating point moves closer to the central efficiency contour with a higher operation efficiency.

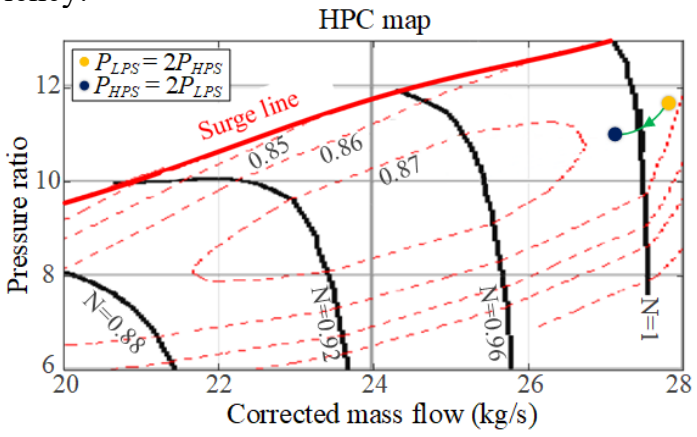

(a)

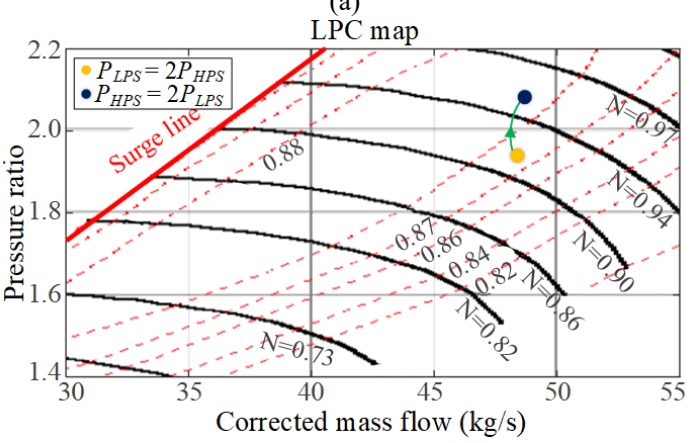

(b)

Fig. 22. Compressor maps in the MTO mode. (a) The HPC map. (b) The LPC map. The arrow in green represents the direction that the proportion of the HPS's power increases.

From the viewpoint of the LPC map, as shown in Fig. 22(b), increasing the proportion of the LPS's power will lead to the decrease of the LPS's speed. Since the thrust is 
proportional to the speed of the LPS, this will decrease the thrust. Moreover, the operating point moves to a lower efficiency contour.

The results in Fig. 22 show that in the high-power settings of engine such as MTO, extracting more mechanical power from the HPS than the LPS can avoid the overspeed and potential instability of the HPS and maintain thrust, which is beneficial for engine stability and efficiency.

\section{Discussion}

In subsection $\mathrm{B}$, it has been proved that the LPR delivers more electrical power than the HPR to the dc bus benefits the HVDC grid stability. In subsection $C$, it has been validated that extracting more mechanical power from the HPS than the LPS can improve engine stability and efficiency. The PGC shown in Fig. 1 cannot fulfill the two goals at the same time due to the Power Coupling Effect. While the APGC shown in Fig. 2 can eliminate this effect by transferring power from the HP channel to the LP channel through the back-to-back converter. This characteristic and relevant control performance has been demonstrated in subsection A.

\section{Conclusion}

In this paper, the Power Coupling Effect of the state-ofthe-art PGC is identified. Due to this effect, it is infeasible to make the LPR output more power to the dc bus and meanwhile extract more power from the HPS. As a result, it is difficult to enhance the stability of HVDC grid and engine simultaneously in the high-power settings of engine. The APGC removes the Power Coupling Effect, enabling the HPS to output more power than the LPS, and the LPR delivers more power than the HPR to the dc bus. Hence the stability of both the HVDC grid and engine can be enhanced. This paper also derives the source and load impedances and provides detailed stability analysis for the HVDC grid. The derived impedance model and analytical findings may be of interest for other researchers who are interested in the stability issue of the onboard dc microgrid. Key performances of the APGC have been verified through simulation and experiment results.

\section{APpendix I. Electrical MAChine PARAMETERS AND OPERATING POINTS USED FOR FIG. 6}

Table II. Parameters of the electrical machine used for Fig. 6.

\begin{tabular}{c|c}
\hline \hline Parameter & Value \\
\hline Nominal power & $45 \mathrm{~kW}$ at $270 \mathrm{~V} \mathrm{dc}$ \\
\hline Nominal speed & $8,000 \mathrm{rpm}$ \\
\hline The number of pole pairs & 3 \\
\hline Stator winding resistance & $53 \mathrm{~m} \Omega$ \\
\hline$d$-axis stator winding inductance & $100 \mu \mathrm{H}$ \\
\hline$q$-axis stator winding inductance & $100 \mu \mathrm{H}$ \\
\hline Magnet flux & $0.04 \mathrm{~Wb}$ \\
\hline Moment of inertia & $0.403 \mathrm{~kg} \cdot \mathrm{m}^{2}$ \\
\hline
\end{tabular}

Table III. Control parameters and operating points used for Fig. 6.

\begin{tabular}{c|c}
\hline \hline Parameter & Value \\
\hline $\begin{array}{c}\text { Control bandwidth for } \\
\text { the dc voltage loop }\end{array}$ & $100 \mathrm{~Hz}$ \\
\hline Damping ratio & 0.707 \\
\hline$k_{D}$ & 0.5 \\
\hline Load power & $5 \mathrm{~kW}$ to $25 \mathrm{~kW}$ \\
\hline $\bar{u}_{q}$ and $\bar{i}_{q L}$ & $\begin{array}{c}\text { They are calculated based on the steady- } \\
\text { state PMG's voltage equations derived } \\
\text { from }(2)\end{array}$ \\
\hline Electrical machine's & $8000 \mathrm{rpm}$ \\
\hline
\end{tabular}

\begin{tabular}{c|c}
\hline speed & \\
\hline $\begin{array}{c}\text { The nominal dc bus } \\
\text { voltage }\end{array}$ & $270 \mathrm{~V}$ \\
\hline \hline
\end{tabular}

\section{APPENDIX II. DERIVATION OF THE SOURCE IMPEDANCE $Z_{S}(S)$ IN (17)}

According to the Kirchhoff Current Law, the current flowing through the HP channel cable can be derived as:

$$
i_{c 1}(s)=\frac{v_{d c}{ }^{r e f}-v_{d c}{ }^{H P}}{k_{D}{ }^{H P}} G_{i d c}{ }^{H P}(s)-v_{d c}{ }^{H P} \cdot s C_{H P}
$$

The current can also be derived from the voltage across the cable and the cable admittances, given as:

$$
i_{c 1}(s)=\left(v_{d c}^{H P}-v_{m b}\right) X_{H P}
$$

Linking (A1) and (A2), the following relation can be derived

$$
v_{d c}^{H P}=\frac{G_{i d c}{ }^{H P} v_{d c}{ }^{r e f}+k_{D}{ }^{H P} X_{H P} v_{m b}}{s C_{H P} k_{D}{ }^{H P}+k_{D}{ }^{H P} X_{H P}+G_{i d c}{ }^{H P}}
$$

Due to the LP channel circuit is identical to that of the HP channel, the local de voltage of the LP channel can also be written as follows:

$$
v_{d c}{ }^{L P}=\frac{G_{i d c}{ }^{L P} v_{d c}^{r e f}+k_{D}{ }^{L P} X_{L P} v_{m b}}{s C_{L P} k_{D}{ }^{L P}+k_{D}{ }^{L P} X_{L P}+G_{i d c}{ }^{L P}}
$$

Under the short circuit condition, the main dc bus voltage is zero, i.e., $v_{m b}=0$. Hence, based on (A3) and (A4), the short circuit current of source subsystem can be expressed as follows:

$$
\begin{aligned}
& i_{s c}(s)=v_{d c}{ }^{H P} X_{H P}+v_{d c}{ }^{L P} X_{L P} \\
& =\frac{G_{i d c}{ }^{H P} X_{H P} v_{d c}{ }^{r e f}}{s C_{H P} k_{D}{ }^{H P}+k_{D}{ }^{H P} X_{H P}+G_{i d c}{ }^{H P}}+\frac{G_{i d c}{ }^{L P} X_{L P} v_{d c}^{r e f}}{s C_{L P} k_{D}{ }^{L P}+k_{D}{ }^{L P} X_{L P}+G_{i d c}{ }^{L P}} \\
& =\sum_{j=L P}^{H P} \frac{G_{i d c}{ }^{j} X_{j}}{s C_{j} k_{D}{ }^{j}+k_{D}{ }^{j} X_{j}+G_{i d c}{ }^{j}} v_{d c}^{r e f}
\end{aligned}
$$

In the open circuit condition, the open circuit voltage can be expressed as follows:

$$
\left(v_{d c}^{L P}-v_{o c}\right) X_{L P}+\left(v_{d c}^{H P}-v_{o c}\right) X_{H P}=v_{o c} \cdot s C_{m b}
$$

Applying (A3) and (A4) into (A6), the open circuit voltage can be derived as follows:

$$
v_{o c}(s)=\frac{\sum_{j=L P}^{H P} \frac{G_{i d c}{ }^{j} X_{j}}{s C_{j} k_{D}{ }^{j}+k_{D}{ }^{j} X_{j}+G_{i d c}{ }^{j}} v_{d c}^{r e f}}{s C_{m b}+\sum_{j=L P}^{H P} \frac{s C_{j} k_{D}{ }^{j} X_{j}+G_{i d c}^{j} X_{j}}{s C_{j} k_{D}{ }^{j}+k_{D}{ }^{j} X_{j}+{G_{i d c}}^{j}}}
$$

Hence, the output impedance of the source subsystem can be derived through dividing (A7) by (A5):

$$
Z_{s}(s)=\frac{v_{o c}(s)}{i_{s c}(s)}=\frac{1}{s C_{m b}+\sum_{j=L P}^{H P} \frac{s C_{j} k_{D}{ }^{j} X_{j}+G_{i d c}{ }^{j} X_{j}}{s C_{j} k_{D}{ }^{j}+k_{D}{ }^{j} X_{j}+{G_{i d c}}^{j}}}
$$

\section{APPENDIX III. SYSTEM PARAMETERS USED IN SECTION III AND IV AND THE CIRCUITRY MODEL OF THE BUCK CONVERTER LOAD}

Table IV. Control parameters and operating points used for Fig. 8

\begin{tabular}{c|c} 
Parameter & Value \\
\hline \hline Parameters of the electrical machine & See Table II \\
\hline Control bandwidth for the inner current loop & $1 \mathrm{kHz}$ \\
\hline Control bandwidth for the dc voltage loop & $100 \mathrm{~Hz}$ \\
\hline Damping ratio & 0.707 \\
\hline $\begin{array}{c}\text { The proportional and integral gains for the } \\
\text { current controller }\end{array}$ & 0.87 and 3908. \\
\hline
\end{tabular}




\begin{tabular}{c|c}
\hline $\begin{array}{c}\text { The proportional and integral gains for the } \\
\text { voltage controller }\end{array}$ & See (12) \\
\hline Speed of the HPG and LPG & $15,000 \mathrm{rpm}$ and \\
$5,000 \mathrm{rpm}$
\end{tabular}

Table V. The definitions and values of parameters used for the input impedance of the buck converter as shown in (36).

\begin{tabular}{|c|c|c|}
\hline Parameter & בDefinition & Value \\
\hline$R_{i c}$ & $\begin{array}{l}R_{i c} \text { is the negative resistance of } \\
\text { the buck converter. } R_{i c}=\frac{\bar{v}_{d c}}{\bar{\iota}_{\text {Load }}}\end{array}$ & $\begin{array}{c}\bar{v}_{d c} \text { and } \bar{l}_{\text {Load }} \\
\text { depend on the } \\
\text { load power and } \\
\text { droop gains }\end{array}$ \\
\hline$\omega_{o}$ & $\begin{array}{c}\omega_{o}=\frac{1}{\sqrt{L_{f} C_{f}}} \text {, where } L_{f} \text { and } C_{f} \text { are } \\
\text { the inductance and capacitance } \\
\text { of the input } L C \text { filter }\end{array}$ & $\begin{array}{c}L_{f}=1.2 \mu \mathrm{H} \text { and } C_{f} \\
=2 \mathrm{mF} . \text { Thus } \omega_{o}= \\
20412 \mathrm{rad} / \mathrm{s}\end{array}$ \\
\hline$Q$ & $\begin{array}{c}Q=\frac{1}{R_{l f}+R_{c f}} \sqrt{\frac{L_{f}}{C_{f}}} \text {, where } R_{l f} \text { and } \\
R_{c f} \text { are the equivalent resistances } \\
\text { of the inductor and capacitor of } \\
\text { the } L C \text { filter }\end{array}$ & $\begin{array}{c}R_{l f}=8 \mathrm{~m} \Omega, R_{c f}= \\
0.01 \Omega . \text { Hence, } Q \\
=13.6\end{array}$ \\
\hline$\omega_{p}$ & $\omega_{p}=-\frac{1}{C_{f} R_{i c}}$ & $\begin{array}{c}C_{f}=2 \mathrm{mF}, R_{\text {ic }}= \\
\frac{\bar{v}_{\text {dc }}}{\overline{\bar{\imath}}_{\text {Load }}} \\
\end{array}$ \\
\hline
\end{tabular}

For the cable impedance, nominal values of cable resistance and inductance are $0.16 \mathrm{~m} \Omega / \mathrm{m}$ and $0.11 \mu \mathrm{H} / \mathrm{m}$, respectively [25]. Based on a business jet aircraft platform, considering the distance from the engine-driven generatorrectifier unit to the main dc bus $(5 \mathrm{~m})$ and the auxiliary power unit-driven generator-rectifier unit to the main dc bus (20m), the cable impedance is set as $3.2 \mathrm{~m} \Omega$ and $2.2 \mu \mathrm{H}$ in this study.

The circuitry of the buck converter load used as a CPL in the simulation and analysis in Section IV is shown in Fig. 23.

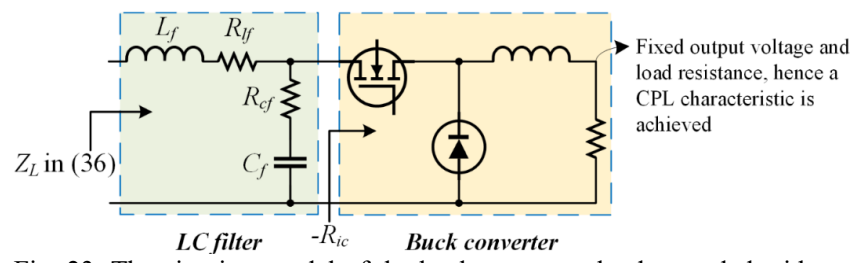

Fig. 23. The circuitry model of the buck converter load cascaded with a $L C$ input filter.

\section{APPENDIX IV. CONSIDERATION OF THE INDUCTOR INSTALLATION IN THE APGC}

It can be seen from Fig. 2 that the four power converters, i.e., HPR, LPR, BTB $\mathrm{B}_{\mathrm{L}}$ converter and $\mathrm{BTB}_{\mathrm{H}}$ converter, are all voltage source converters (VSC). To make them operate compatibly, inductors should be deployed to separate these VSCs. Moreover, inductors can filter high frequency pulse-width modulation harmonics generated by the switching actions of power devices. There are four possible configurations with different locations of inductors, as shown in Fig. 24.

In Fig. 24(a) and (b), an inductor, denoting as $L_{2}$, is placed at the front end of the $\mathrm{BTB}_{\mathrm{H}}$ converter. In this case, the terminals voltages of the HPG are limited within $\frac{v_{d c}}{\sqrt{3}}$ using the typical space vector pulse-width modulation (SVPWM) [26], where $v_{d c}$ is the main dc bus voltage. The value of $v_{d c}$ is considered as $270 \mathrm{~V}$ to follow the MIF-STD$704 \mathrm{~F}$ standard. Hence, for some permanent magnet-based generators, such as the electrical machine [27] developed under the frame of the Clean Sky project, it means that the field-weakening operation is still needed for the HPG with the architecture shown in Fig. 24(a) and (b).

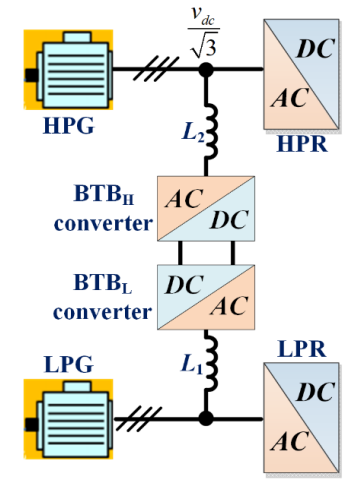

(a)

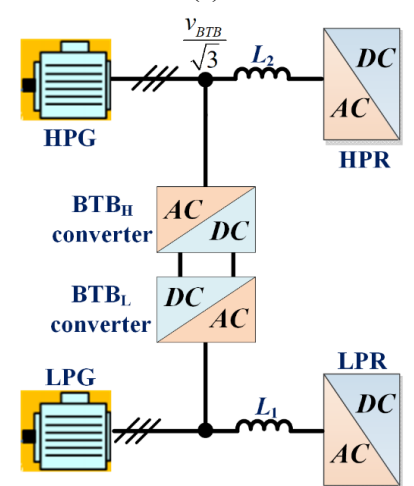

(c)

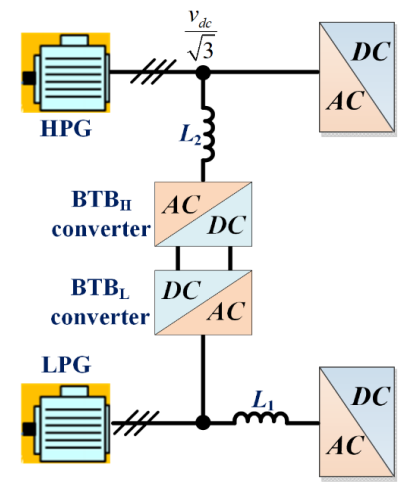

(b)

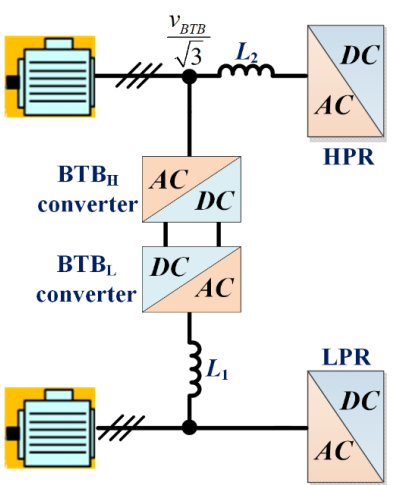

(d)

Fig. 24. The four configurations with different locations of inductors. (a) $L_{1}$ and $L_{2}$ are at the front end of the $\mathrm{BTB}_{\mathrm{L}}$ and $\mathrm{BTB}_{\mathrm{H}}$ converter. (b) $L_{1}$ is at the front end of the LPR, $L_{2}$ is at the front end of the $\mathrm{BTB}_{\mathrm{H}}$ converter. (c) $L_{1}$ and $L_{2}$ are at the front end of the LPR and HPR. (d) $L_{1}$ is at the front end of the $\mathrm{BTB}_{\mathrm{L}}$ converter, $L_{2}$ is at the front end of the HPR.

In Fig. 24(c) and (d), $L_{2}$ is deployed at the front of the HPR. In this case, terminals voltages of the HPG are limited within $\frac{v_{B T B}}{\sqrt{3}}$ using the SVPWM, where $v_{B T B}$ is the dc-link voltage within the BTB converter. By increasing the voltage of $v_{B T B}$, the HPG can operate at a high speed without field-weaking control. Hence the power losses within the HPG and HPR can be reduced [11]. The difference between Fig. 24(c) and (d) is the location of inductor $L_{1}$. Since in most cases, most of the LP channel' power goes through the LPR to feed the onboard loads, and a relatively small proportion of power is transferred through the BTB converter, phase current of the LPR is larger than that of the $\mathrm{BTB}_{\mathrm{L}}$ converter. Placing $L_{1}$ at the front end of the $\mathrm{BTB}_{\mathrm{L}}$ converter instead of the LPR can reduce the power losses in the inductor $L_{1}$. To conclude above, the configuration of inductors shown in Fig. 24(d) are chosen to build the APGC as shown in Fig. 2.

\section{Acknowledgement}

The authors would like to thank the reviewers and the editors for their helpful and insightful comments on an earlier draft of this paper. The author Xiaoyu Lang also thanks the studentship from China Scholarship Council.

\section{REFERENCES}

[1] M. Lukic, P. Giangrande, A. Hebala, S. Nuzzo and M. Galea, "Review, Challenges, and Future Developments of Electric Taxiing 
Systems," IEEE Trans. Transport. Electrific., vol. 5, no. 4, pp. 14411457, Dec. 2019.

[2] P. Giangrande et al., "Considerations on the Development of an Electric Drive for a Secondary Flight Control Electromechanical Actuator," IEEE Trans. Ind. Appl., vol. 55, no. 4, pp. 3544-3554, July-Aug. 2019.

[3] H. B. Enalou, X. Lang, M. Rashed and S. Bozhko, "Time-Scaled Emulation of Electric Power Transfer in the More Electric Engine," IEEE Trans. Transport. Electrific., vol. 6, no. 4, pp. 1679-1694, Dec. 2020.

[4] H. B. Enalou, S. Bozhko, M. Rashed, and J. Le-Peuvedic, "Potential improvements in turbofan's performance by electric power transfer," SAE Tech. Paper, 2018-01-1962, 2018

[5] B. Sarlioglu and C. T. Morris, "More electric aircraft: Review, challenges, and opportunities for commercial transport aircraft," IEEE Trans. Transport. Electrific., vol. 1, no. 1, pp. 54-64, Jun. 2015.

[6] C. Gu et al., "A Multiport Power Conversion System for the More Electric Aircraft," IEEE Trans. Transport. Electrific., vol. 6, no. 4, pp. 1707-1720, Dec. 2020

[7] R. Todd and A. J. Forsyth, "HIL emulation of all-electric UAV power systems," in Proc. IEEE Energy Convers. Congr. Expo., Sep. 2009, pp. 411-416.

[8] K. Muehlbauer and D. Gerling, "Two-generator-concepts for electric power generation in more electric aircraft engine," in Proc. 19 Int. Conf. Elect. Mach., 2010, pp. 1-5.

[9] Y. Jia and K. Rajashekara, "An Induction Generator-Based AC/DC Hybrid Electric Power Generation System for More Electric Aircraft," IEEE Trans. Ind. Appl., vol. 53, no. 3, pp. 2485-2494, June 2017.

[10] C. Wang, T. Yang, H. Hussaini, Z. Huang and S. Bozhko, "Power Quality Improvement Using an Active Power Sharing Scheme in More Electric Aircraft," IEEE Trans. Ind. Electron., doi: 10.1109/TIE.2021.3076401.

[11] X. Lang et al., "A Dual-Channel-Enhanced Power Generation Architecture With Back-to-Back Converter for MEA Application," IEEE Trans. Ind. Appl., vol. 56, no. 3, pp. 3006-3019, May-June 2020.

[12] L. Tarisciotti, A. Costabeber, L. Chen, A. Walker and M. Galea, "Current-Fed Isolated DC/DC Converter for Future Aerospace Microgrids," IEEE Trans. Ind. Appl., vol. 55, no. 3, pp. 2823-2832, May-June 2019

[13] Balaghi Enalou, Hossein, and Serhiy Bozhko. "Performance Improvement of Turbofans by Electric Power Transfer." Journal of Turbomachinery, 142.11, 2020.

[14] Balaghi Enalou, Hossein, and Serhiy Bozhko. "Electric Power Transfer Concept for Enhanced Performance of the More Electric Engine." Journal of Engineering for Gas Turbines and Power, 2021.

[15] J. M. Guerrero, J. C. Vasquez, J. Matas, L. G. de Vicuna, and M. Castilla, "Hierarchical control of droop-controlled AC and DC microgrids-A general approach toward standardization," IEEE Trans. Ind. Electron., vol. 58, no. 1, pp. 158-172, Jan. 2011.

[16] S. Bozhko et al., "Development of Aircraft Electric StarterGenerator System Based on Active Rectification Technology," IEEE Trans Transport. Electrific., vol. 4, no. 4, pp. 985-996, Dec. 2018.

[17] Q. Wang et al., "A Low-Complexity Optimal Switching TimeModulated Model-Predictive Control for PMSM With Three-Level NPC Converter," IEEE Trans. Transport. Electrific., vol. 6, no. 3, pp. 1188-1198, Sept. 2020.

[18] R. D. Middlebrook, "Input filer consideration in design and application of switching regulators," in Proc. IEEE IAS Annu. Meet., Chicago, USA, Oct. 1976, pp. 336-382.

[19] A. Riccobono and E. Santi, "Comprehensive Review of Stability Criteria for DC Power Distribution Systems," IEEE Trans. Indus. Appl., vol. 50, no. 5, pp. 3525-3535, Sept.-Oct. 2014.

[20] J. Yang, G. Buticchi, C. Gu, S. Günter, H. Zhang and P. Wheeler, "A Generalized Input Impedance Model of Multiple Active Bridge Converter," IEEE Trans. Transport. Electrific., vol. 6, no. 4, pp. 1695-1706, Dec. 2020.

[21] Aircraft Electric Power Characteristics, American Military Std. MILSTD-704F.

[22] V. Madonna, P. Giangrande and M. Galea, "Electrical Power Generation in Aircraft: Review, Challenges, and Opportunities," IEEE Trans. Transport. Electrific., vol. 4, no. 3, pp. 646-659, Sept. 2018.

[23] R. Burgos, P. Kshirsagar, A. Lidozzi, F. Wang, and D. Boroyevich, "Mathematical model and control design for sensorless vector control of permanent magnet synchronous machines," Proc. IEEE Workshops COMPEL, Jul. 2006, pp. 76-82.

[24] S. K. Pidaparthy, B. Choi and Y. Kim, "A Load Impedance Specification of DC Power Systems for Desired DC-Link Dynamics and Reduced Conservativeness," IEEE Trans. Power Electron., vol. 34, no. 2, pp. 1407-1419, Feb. 2019.

[25] L. Han, J. Wang and D. Howe, "Small-signal Stability Studies of a 270V DC More-Electric Aircraft Power System," 2006 3rd IET International Conference on Power Electronics, Machines and Drives - PEMD 2006, Dublin, Ireland, 2006, pp. 162-166.

[26] H. Gashtil, V. Pickert, D. J. Atkinson, M. Dahidah and D. Giaouris, "Improved Voltage Boundary with Model-Based Control Algorithm for Increased Torque in the Field Weakening Region of Induction Machines," IEEE Trans Transport. Electrific., early access, 2021, doi: 10.1109/TTE.2020.3048306.

[27] S. Bozhko, M. Rashed, C. I. Hill, S. S. Yeoh and T. Yang, "FluxWeakening Control of Electric Starter - Generator Based on Permanent-Magnet Machine," IEEE Trans Transport. Electrific., vol. 3, no. 4, pp. 864-877, Dec. 2017.

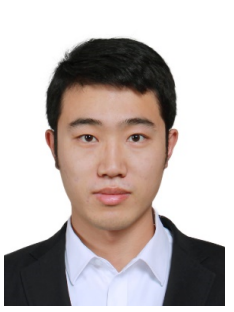

Xiaoyu Lang received the B.S. degree and M.Sc. degree with Honors in electrical engineering from the Harbin Institute of Technology (HIT), Harbin, China, in 2015 and 2017, respectively. $\mathrm{He}$ is currently working towards the Ph.D degree at the Power Electronics, Machines and Control Group, The University of Nottingham, Nottingham, NG7 2RD, U.K. His research interests include high speed machine drives, advanced integrated power generation center for more electric aircrafts, and

DC microgrid stability.

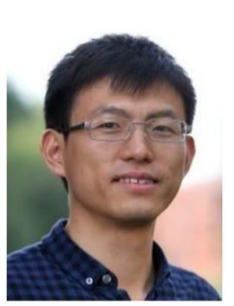

Tao Yang (M'16-SM'20) received the Ph.D. degree in electrical engineering from the University of Nottingham, Nottingham, U.K., in 2013.

Since then, he has been a Researcher and an Associate Professor with the Power Electronics, Machines and Control Group, University of Nottingham. His research interests include aircraft electrical power systems and high-speed motor drives for aerospace applications.

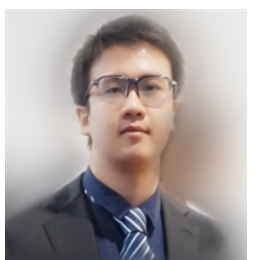

Zhen Huang (M'20) received the B.Eng. (hons.) degree in electrical and electronics engineering, and the Ph.D. in electrical engineering from the University of Nottingham, Nottingham, U.K., in 2015 and 2019, respectively.

Since January 2020, he has been a Research Fellow with the Power Electronics, Machines and Control Group, University of Nottingham. His research interests include high-speed motor drives, multilevel converters modulation, and on-board electrical power system protection.

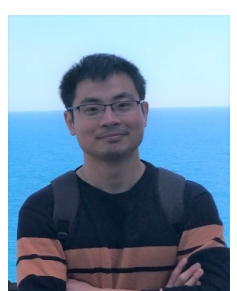

Cheng Wang was born in Jiangsu, China. He received the B.Eng. and M.Sc. degrees in electrical engineering from Nanjing University of Aeronautics and Astronautics, Nanjing, China, in 2013 and 2016, respectively. Since 2017, he is currently working toward the Ph.D. degree in electrical and electronic engineering with the Power Electronics, Machines, and Control Group, University of Nottingham, Nottingham, U.K. His research interests include control and power quality improvement in area of electric DC power systems. 


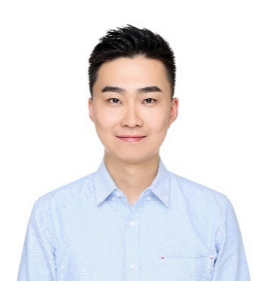

Zhenyu Wang received the B.S. degree in Electrical Engineering, from Chongqing University, Chongqing, China in 2012, and the M.S. and Ph.D. degree in Power Electronics from the University of Nottingham, Nottingham, UK, in 2014 and 2018, respectively.

$\mathrm{He}$ is currently a Research Fellow with the Power Electronics, Machines and Control (PEMC) Group at the University of Nottingham, Nottingham, UK. He was a visiting scholar with the LEMUR Research Group at the University of Oviedo, Spain, from April 2016 to February 2017. His Research interests include $\mathrm{SiC}$ and $\mathrm{GaN}$ devices and applications, DC-DC converters for marine and aerospace applications, magnetic components for power.

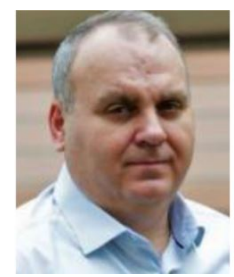

Serhiy Bozhko (M'96-SM'18) received his M.Sc. and $\mathrm{Ph} . \mathrm{D}$. degrees in electromechanical systems from the National Technical University of Ukraine, Kyiv City, Ukraine, in 1987 and 1994, respectively. Since 2000, he has been with the Power Electronics, Machines and Controls Research Group of the University of Nottingham, United Kingdom, where currently he is Professor of Aircraft Electric Power Systems and Director of the Institute for Aerospace Technology. He is leading several EU- and industry funded projects in the area of aircraft electric power systems, including power generation, distribution and conversion, power quality, control and stability issues, power management and optimization, as well as advanced modeling and simulations methods.

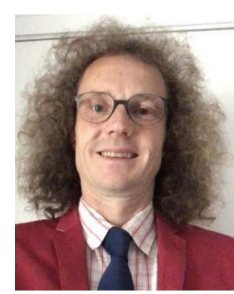

Patrick Wheeler (Fellow, IEEE) received the B.Eng. (hons.) degree in electrical engineering and the Ph.D. degree for his work on matrix converters from the University of Bristol, Bristol, U.K., in 1990 and 1994, respectively.

In 1993, he moved to the University of Nottingham, Nottingham, U.K., where he worked as a Research Assistant with the Department of Electrical and Electronic Engineering. In 1996, he became a Lecturer with the Power Electronics, Machines and Control Group, University of Nottingham, where he has been a Full Professor since January 2008. From 2015 to 2018, he was the Head of the Department of Electrical and Electronic Engineering, University of Nottingham. He has authored/coauthored more than 700 academic publications in leading international conferences and journals.

Prof. Wheeler is currently the Head of the Power Electronics, Machines and Control Research Group, Global Director of the University of Nottingham's Institute of Aerospace Technology and was the Li Dak Sum Chair Professor in Electrical and Aerospace Engineering from 2016 to 2020. $\mathrm{He}$ is a member of the IEEE Power Electronics Society Administrative Committee (PEL's AdCom). He is also the Vice-President for Technical Operations of the IEEE Power Electronics Society (PELS). 